\title{
A review of urban energy system models: approaches, challenges and opportunities
}

\author{
James Keirstead $^{\mathrm{a}, *}$, Mark Jennings ${ }^{\mathrm{a}}$, Aruna Sivakumar ${ }^{\mathrm{b}}$ \\ ${ }^{a}$ Department of Civil and Environmental Engineering \\ Imperial College London, London, UK, SW7 $2 A Z$ \\ ${ }^{b}$ Centre for Transport Studies \\ Imperial College London, London, UK, SW7 $2 A Z$
}

\begin{abstract}
Energy use in cities has attracted significant research in recent years. However such a broad topic inevitably results in number of alternative interpretations of the problem domain and the modelling tools used in its study. This paper seeks to pull together these strands by proposing a theoretical definition of an urban energy system model and then evaluating the state of current practice. Drawing on a review of 219 papers, five key areas of practice were identified - technology design, building design, urban climate, systems design, and policy assessment - each with distinct and incomplete interpretations of the problem domain. We also highlight a sixth field, land use and transportation modelling, which has direct relevance to the use of energy in cities but has been somewhat overlooked by the literature to date. Despite their diversity, these approaches to urban energy system modelling share four common challenges in understanding model complexity, data quality and uncertainty, model integration, and policy relevance. We then examine the opportunities for improving current practice in urban energy systems
\end{abstract}

* Corresponding author

Email addresses: j.keirstead@imperial.ac.uk (James Keirstead), m.jennings09@imperial.ac.uk (Mark Jennings), a.sivakumar@imperial.ac.uk (Aruna Sivakumar) 
modelling, focusing on the potential of sensitivity analysis and cloud computing, data collection and integration techniques, and the use of activity-based modelling as an integrating framework. The results indicate that there is significant potential for urban energy systems modelling to move beyond single disciplinary approaches towards a sophisticated integrated perspective that more fully captures the theoretical intricacy of urban energy systems. Keywords: cities, energy, modelling, transport

\section{Introduction}

Over $50 \%$ of the world's population currently lives in urban areas, a figure expected to rise to $70 \%$ by 2050 [1]. This trend can be explained in large part by economic and social forces, as cities offer their citizens new opportunities for business, education, security, and community [2, 3]. However supporting these activities requires significant resource flows, leading to both local and global environmental pollution [4]. For example, a recent assessment suggests that two-thirds of global primary energy consumption can be attributed to urban areas, which in turn leads to $71 \%$ of global direct energy-related greenhouse gas emissions [5].

Energy resources are not consumed for their own sake but represent derived demands. Barrels of oil and kilowatt-hours of electricity are used to satisfy the services requirements of an urban population as they work, heat their homes, move about the city and perform other activities. The systems that mediate between the consumption of raw fuels and these ultimate service demands therefore constitute vital infrastructures that determine the overall performance and environmental impact of urban energy use. Researchers from a number of fields have accordingly begun to look at how these systems can be modelled, with a view to understanding and improving their 
performance.

The goal of this paper is to review the literature on urban energy systems (UES) modelling in order to assess the current state of practice and answer three major questions. First, what approaches are used to model urban energy systems? Addressing this question necessarily requires describing the conceptualization of urban energy systems, as the scale and scope of analysis will inform the choice of method. Secondly, what challenges do urban energy system modellers face? To what extent are modelling attempts stifled by insufficient data or, alternatively, are there methodological issues which need to be resolved before appropriate conclusions can be drawn? Finally, what opportunities are there for advancing urban energy models? This is a forward-looking question, seeking to identify new trends and how these relate to existing practice. It is hoped that by identifying these obstacles, we can highlight areas where cooperation between researchers might be especially fruitful.

The paper is presented as follows. We begin by offering a definition of urban energy systems and a description of our review methodology (Section 2). Each of the three research questions is then answered in turn. Section 3 presents a review of urban energy system modelling approaches, highlighting key features such as the temporal and spatial scales of analysis, the methods used, and the target audiences for the work. Next we describe the challenges reported by these studies (Section 4) and the opportunities for overcoming these barriers (Section 5). The conclusion summarizes the major findings of the paper, in particular highlighting the potential of activity and agent-based modelling methods, alongside improved data standards and computational advances, to create integrated policy-responsive models of urban energy use. 


\section{Definitions and methodology}

\subsection{Defining an urban energy system}

Before beginning the review, we must define what is meant by an "urban energy systems model". The aim here is to characterize the major features of such tools in order to determine whether they appropriately address the major issues, either individually or collectively.

As a starting point, we refer to Jaccard's 2005 definition of an energy system as "the combined processes of acquiring and using energy in a given society or economy." (p. 6) This definition is particularly helpful as it identifies three salient features of urban energy use:

combined processes Delivering energy services requires many different steps including resource extraction, refining, transportation, storage, and conversion to end service. While the urban environment may be physically separate from many of these processes, they should be considered in an overall analysis if they are ultimately being used to service urban demands. For example, urban greenhouse gas emissions inventories typically include emissions from ex-urban electricity generation as a minimum and can be expanded to include a range of life-cycle or upstream emissions [7].

acquiring and using Energy systems represent a balance between supply and demand. Historically cities might be seen as centres of passive demand which must be supplied from an ex-urban source, but recent work suggests that there are now significant opportunities for in-city energy generation [8]. Given these possibilities, urban energy systems should be conceived of as including both sides of the supply and demand equation. 
given society or economy An energy system is a socio-technical system, comprised of more than just pipelines, fuels, and engineering equipment [e.g. 9]. Markets, institutions, consumer behaviours and other factors affect the way technical infrastructures are constructed and operated. Urban energy systems therefore need to be viewed more widely and account for local context.

The most difficult part about adapting this generic definition of an energy system to one that is specifically "urban" lies in defining the boundaries of a city. This is a common problem, faced by groups such as the UN Population Division [10], industrial ecologists [11], economic geographers [2] and others. When considering urban energy systems, there are arguably three alternative definitions (adapted from [12]):

- pure geographic, i.e. the urban energy system consists only of those technologies that lie within a city's administrative boundaries;

- geographic-plus, i.e. everything within the administrative boundaries plus easily traceable upstream flows, like electricity consumption;

- pure consumption, i.e. the energy system encompasses all energy activities of a city's occupants wherever they occur. For example, attributing a resort's energy consumption and emissions to the home cities of the visiting tourists.

For the purpose of this review, we adopt the "geographic-plus" definition of urban. The pure geographic definition is too restrictive, notably omitting electricity flows arising from outside the city, and the pure consumption approach is too broad. A geographic-plus definition of urban reflects the daily practice of many leading cities [13], capturing the influence of urban form, 
economic function, and attributes of the energy supply system. It potentially excludes lifecycle and trade-related issues (e.g. the ex-urban embodied emissions of goods and services).

Finally we define "model" after Rosen [14]; that is, a formalised representation of a natural system with its own internally consistent rules. This formal system can be implemented in many different ways, but in practice and in this review, we primarily mean mathematical models and computer codes.

These considerations lead to the following working definition of an urban energy system model: a formal system that represents the combined processes of acquiring and using energy to satisfy the energy service demands of a given urban area.

\subsection{Review methodology}

The above definition casts a wide net and could encompass numerous sectors, techniques, and application domains. We therefore conducted a broad survey of the literature in order to identify the diversity of current practice.

The review was performed by searching the ISI Web of Knowledge database ${ }^{1}$ for the terms (urban OR city) energy model in the topic or title fields and this resulted in 2019 results. In order to identify a manageable subset of papers, the results were initially filtered by two criteria: the publication had to be in English (95.2\% of the full data set) and be a published journal article or review ( $72.3 \%$ of the full data set). This notably omits conference papers which accounted for $26.5 \%$ of the full result set, but still leaves a total of 1377 records. The results were further filtered by excluding subject areas deemed irrelevant to our urban energy system definition, such as biological or health

\footnotetext{
${ }^{1}$ http://www. isiknowledge.com
} 
sciences. Studies from the field of meteorology and atmospheric sciences were also omitted, although as will be shown below, urban climate studies with relevance to energy systems did still appear in the review sample (e.g. studies considering how urban heat island effects and ventilation in built-up areas shape urban energy demand). This left 373 studies, representing the subject areas of engineering (50.4\% of records), energy and fuels (38.9\%), environmental sciences and ecology $26.3 \%)$, construction and building technology $(16.9 \%)$, and business and economics $(7.00 \%) .^{2}$

While manually categorizing these papers, it was noted that 83 studies were not directly relevant to the aims of this review despite matching the search terms; these were primarily papers on urban ecology. Furthermore when exporting the individual search records from Web of Knowledge, 71 records were found to be missing when compared to the tallies presented in the aggregate analysis above. The reason for this discrepancy is not clear and therefore readers should treat the above descriptive statistics as indicative results only. This therefore leaves a set of 219 papers for detailed analysis and Figure 1 shows the distribution of publication dates for these papers. The identified papers primarily represent the past decade (the median publication year is 2008) and confirm that the review is effectively an assessment of current practice rather than a survey of past trends.

The studies were then reviewed and classified as described in the next section. During this process, it was observed that the identified sample omitted at least one prominent area of research relevant to urban energy systems, namely transport and land use modelling. Land use-transport models seek to model urban activities and the demand for transport infrastructure. Al-

\footnotetext{
${ }^{2}$ Note that studies can be multiply classified, hence the listed percentages do not add up to 100 .
} 


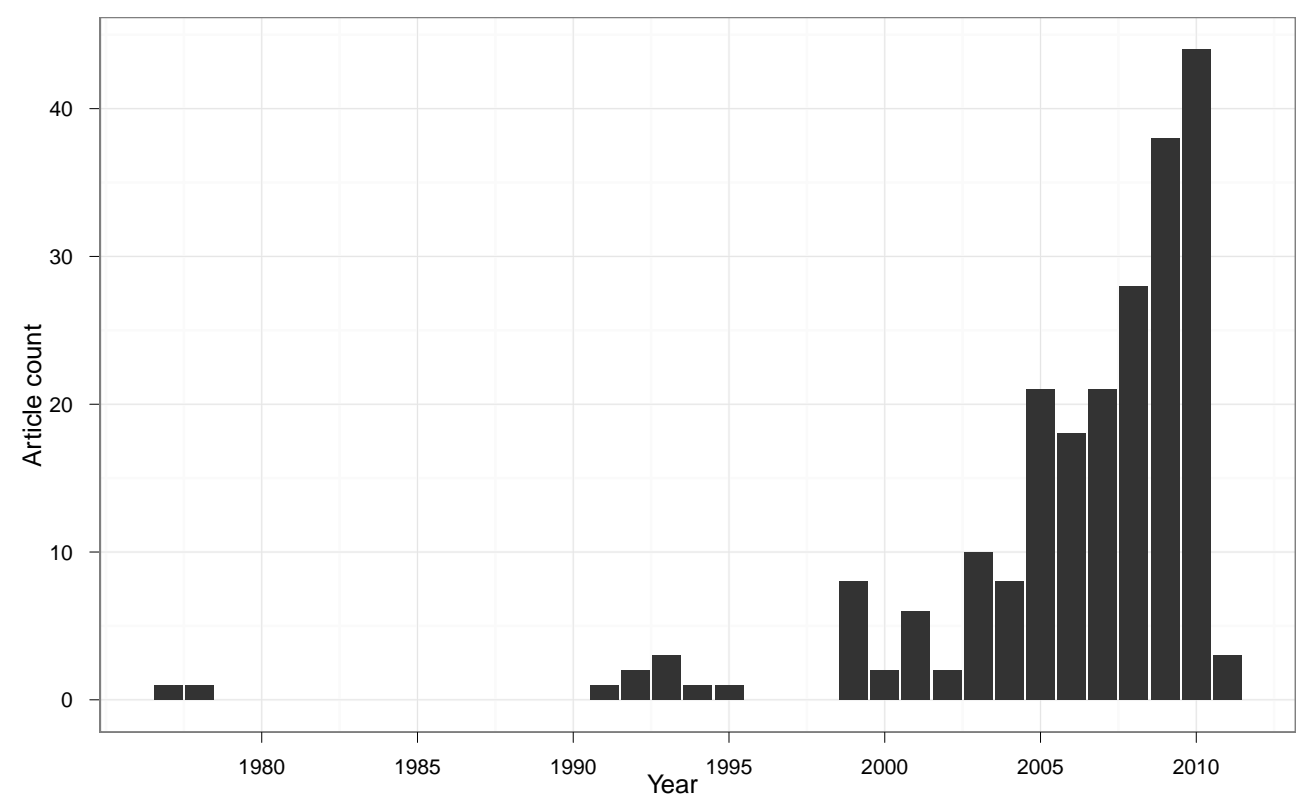

Figure 1: Distribution of publication dates for 219 ISI Web of Knowledge papers matching the topic or title (urban OR city) energy model and filtered for relevance.

though they have been used for decades, it is only very recently that researchers have identified the benefits of such models to the wider urban energy systems community and we expect that it will take several years before these papers use the appropriate keywords that would identify them as a part of the above search sample. A supplementary review on this topic was therefore conducted and Section 3.6 describes this body of research in some detail as they have traditionally been left out of most UES reviews.

\section{Approaches}

To identify the major approaches used in urban energy systems modelling, the papers were scored according to their main attributes. These features include:

Temporal and Spatial Scale The values assigned for each of these cate- 
gories depend upon the finest grain of model output described in the paper. For example, if a model used hourly electricity profiles as input in order to make an annual investment decision, the temporal scale would be classified as annual. However if the hourly profiles were used for hourly decisions in an operational model, then the temporal scale would be hourly. A similar approach was used for defining a paper's spatial scale. Since models often taken multiple inputs, it was felt that defining the resolution based on a model's inputs would be too inconsistent for a comparative analysis.

Method We considered both the major and minor techniques used in the paper's analysis. For example, papers labelled "optimization" could also be sub-categorized as using mixed-integer linear programming or multi-objective formulations. The cluster analysis described below was only performed on the primary method.

Application and Audience We tried to assess the model's primary application (e.g. system planning, technology design, operational control) and target audience (e.g. policy makers, engineers). As papers do not always state this explicitly, these categorizations are more subjective than the other criteria and so a single "application" variable was used in the analysis below.

Supply and Demand We examined how each model represented the supply and demand sides of the energy system. Both attributes were assigned one of three values: none (not considered), exogenous (specified by the user as a model input), or endogenous (determined by the model as an output). 
These data were then encoded to indicate if they were ordinal (spatial and temporal scales) or nominal (all other criteria) data and a two-step cluster analysis was performed using R's cluster package [15, 16]. First, an agglomerative nesting clustering analysis was performed to identify the number of distinct clusters within the data set. Using the daisy algorithm with the Gower distance metric, the dissimilarity matrix for the data set was calculated and this was used as input for the agnes clustering routine; the results suggested five distinct groupings.

Next, partitioning around medoids (pam) clustering was used to identify the attributes of each cluster. These attributes provide an indicative description of each model type found within the data set, as shown in Table 1 . The rest of this section will examine each of these categories in detail.

\begin{tabular}{lcccccc}
\hline Category & Spatial & Temporal & Method & Supply & Demand & $n$ \\
\hline Technology design & Technology & Monthly & Simulation & endogenous & none & 33 \\
Building design & Building & Annual & Simulation & none & endogenous & 56 \\
Urban climate & Sub $1 \mathrm{~km}$ & Hourly & Simulation & none & endogenous (indirect) & 36 \\
System design & District & Static & Optimization & endogenous & exogenous & 39 \\
Policy assessment & City & Static & Empirical & exogenous & exogenous & 55 \\
Transportation & District* & Dynamic & Econometric & endogenous & endogenous & - \\
\hline
\end{tabular}

Table 1: Medoid characteristics of main paper types described by the review. The "transportation" models were not part of the main clustering analysis, but their typical features are listed here for comparison. *The spatial unit of analysis for transportation models is typically the transportation analysis zone (approximately 3000-5000 people) but can be as detailed as the precise latitude and longitude coordinates of a single point.

\subsection{Technology design}

Technology design studies are characterized by a small spatial scale, generally considering a single piece of technology. $70 \%$ of the 33 studies identified here used simulation techniques to perform the analysis, although experimen- 
tal work was another popular choice (18\%). Temporal resolutions ranged from seconds in the case of vehicle performance studies [17, 18], hourly or daily for solar energy systems [e.g. 19 21], through to annual or static analyses where the goal was to consider life-cycle performance issues [e.g. 22, 23].

The studies focused on energy supply technologies including the design and performance of urban wind turbines [22 28]; solar energy systems including PV, hot water, and cooling [19 21, 29 39]; other heating or cooling technologies, including fuel cells 40 43]; vehicle performance under urban load cycles [17, 18]; and waste-to-energy systems [44 48]. In two-thirds of these models, the demand side was not considered at all; in the remaining third, energy demands were specified exogenously to the model. The models might therefore be characterized as calculating supply-side parameters related to technology design or, in some cases, operation.

\subsection{Building design}

The 56 studies within the "building design" cluster are less homogenous. Broadly speaking the studies might be classified as dealing with building design and renovation [49 52], energy demand estimation in the built environment [53 56], urban climate as it directly affects buildings [57 60], urban planning and policy [61-63], and transport [64 66]. They represent a range of spatial scales, from single buildings [67 78] to groups of buildings in a street or district [79 81] or the whole city [82 89], and the behaviour of individuals [90 92]. Temporal scale is also varied, with the three most common scales being static [e.g. 87, 89, 93], annual time-series [e.g. 52, 67, 69], or hourly [e.g. 54, 73, 77].

What does unite these studies is their emphasis on the demand side of the energy system. $90 \%$ of the studies considered the demand side endogenously, that is simulating the demands for heat, cooling, power and transport under 
different conditions or policy scenarios. In $70 \%$ of the studies, supply-side issues were not considered at all and when they were (20\%), it was in the assumption of carbon intensity factors so as to convert energy demands into carbon emissions [e.g. 67].

Like the technology design studies, these papers rely primarily on simulation and experimental techniques. However the precise methods have changed over time, as revealed when considering only those papers dealing with building retrofits. For example, one of the first simulation papers in our sample modelled the optimal home-owner strategy for renovating a flat using BREDEM 8 [94]. BREDEM is a domestic energy model, based upon the physics of heat flux in buildings, and can be used to estimate the annual consumption from monthly estimates of space heating, water heating, cooking, appliances and lighting [95]. The model considered retrofit measures (e.g. insulation, double glazing, ventilation controls and alternative heating systems) in terms of their discounted energy savings to initial investment ratio.

Simulation models involving the use of fuzzy logic and linguistic variables were presented shortly thereafter, with the intent of estimating the loaddemand profiles (with uncertainty) of domestic customers when introducing demand side management programs [96, 97]. Further models built on this premise have examined the energy consumption of Osaka, Japan [98] and the impact of energy conservation programs [63, 99]. City-scale analysis was also seen in Bennett [100], who presents a method for breaking down energy use in a city such that accurate energy auditing of cities can be completed and potential energy savings assessed. More recently, urban retrofit simulation models have largely concentrated on urban-scale processes that may be used to retrofit agglomerations of dwellings and associated service provision, for 
various audiences and purposes [101-106]. This has been in parallel with research at both building [107, 108] and district scale [109 111].

Other modelling techniques seen within this cluster include the use of GISbased tools [62], computational fluid dynamics [58, 72, 77], and agent-based modelling approaches [112]. There were several examples of field studies as well, rather than numerical simulation, including most notably an assessment of thermal comfort in English low-income dwellings before and after retrofitting 90 .

Overall the methodological focus of these studies, like those in the technology design cluster, suggests that they are aimed primarily at engineers and scientists - i.e. those developing and improving the core technologies and less focus is placed on how these systems might integrate within the wider urban energy system.

\subsection{Urban climate}

The 36 studies of the "urban climate" cluster are notable for their indirect focus on calculating energy demands for heating, cooling and lighting; that is, these models do not deal with energy services directly but calculate the temperatures and lighting conditions within buildings that will in turn determine energy service demands. In many cases, the use of this climatic data for energy service calculations is not mentioned although others do make an explicit energy link. Examples of this latter type include studies of London's heat island and its impact on energy and health issues [113, 114], an assessment of electricity demands for air conditioning in Tokyo's urban heat island [115], and examining the impact of weather on domestic electricity consumption in the Mediterranean [116].

The studies operated at two main spatial scales. The first group looked at the effect of urban climate and heat island effects on buildings [117-126] 
and the second looked at a larger district scale [127-133], including street cross-sections [134-139] or raster grid of several hundred meters [140, 141]. Temporal resolution was hourly in two-thirds of the studies, and daily or monthly in $22 \%$.

The studies represent a mix of pure research - for example, assessing the balance of anthropogenic heat emissions and natural solar radiation in London's overall heat balance [140] - and more applied studies, which focus on both methodological issues [114, 133] and specific policy issues such as building design or urban planning regulations [e.g. 141, 142].

\subsection{System design}

The next major cluster is the "system design" studies, which are characterized primarily by their use of optimization techniques ( $72 \%$ of the 39 studies in the cluster). The typical problem definition in these studies is, for an exogenously-specified pattern of energy service demands, to determine the combinations of capital equipment and operating patterns to meet some objective subject to constraints (e.g. what is the lowest cost system that satisfies heat and power demands subject to a carbon emissions reduction target?).

Given that most urban energy systems in place today will still be in place in the near to long-term, largely as a consequence of embedded infrastructural decisions [143], an important subset of the system design category are those models concerned with designing the retrofit of urban energy systems, specifically those that model the improvement of existing buildings and/or heating networks within urban areas. Retrofit is defined here as "a planned action intended to improve upon existing energy infrastructure with the provision of appropriate technology and methods". Manfren et al. [144] has previously reviewed studies of this kind, focusing particularly on distributed 
generation techniques. Indeed most of the studies identified here do consider combined heat and power and district energy situations, although our cluster includes studies that consider other planning activities such as urban power networks more generally [145 147], hydrogen infrastructure [148], waste management [149], and transport systems [150]. Optimization has also been used for impact assessment [e.g. the costs of power outages, 151 154] and policy assessment [155 157]. Specific techniques include linear programming (LP) [158 160, mixed-integer linear programming (MILP) [161 164], and multiobjective optimization [165 167]. We provide here a brief history of models intended for retrofitting existing systems, such that the development of integrated land-use transport models in section 3.6 may be contrasted and compared.

Gustafsson et al. [168] were the first identified to use optimisation techniques to assess the impact of district heating rates on the life-cycle cost (LCC) of retrofit strategies for multi-family buildings. A LCC typically consists of conflated capital, installation and operational costs. Gustafsson and Karlsson [169] uses objective functions that minimized the LCC for a range of retrofit measures, generally with case studies of multi-family buildings in Sweden [170 173], particularly for insulation interventions [174], fenestration retrofits [175] and more recently for domestic hot water and space heating refurbishment of a block of flats [163]. These papers make use of traditional mathematical programming for the most part with mixed integer linear programming (MILP) providing a useful tool for analysis. Henning [176] cites Gustafsson's earlier work [172] in his development of the MODEST energy model. This is a linear programming (LP) tool which may be used by utilities seeking to minimize the investment costs of upgrading community scale energy systems. This work was followed by the presentation of a LP model 
using factorial design for sensitivity analyses of investment decisions in a district heating system with an associated combined heat and power (CHP) plant [177].

System design studies typically consider either the entire city or a specific sub-district, although similar techniques can be applied to buildings [162, 178]. District scale models have been the dominant choice of spatial optimisation since at least the year 2000 [179 189] whilst others have focused on building stock models [190 193]. It is reflective of the recent advances in both programming software and computational hardware that some researchers have increasingly pushed from district scales towards urban scale models [194 201].

The temporal resolution of these models has also changed. Within our sample, $51 \%$ of the models performed static analyses, although multi-period assessments at hourly, monthly, annual, and decadal resolutions were also seen. For example, Rolfsman [202] describes a MILP for minimizing the total cost of a municipal energy system, by either investing in new plant or retrofitting buildings (or both), wherein he divides a year into periods of 3 hours duration. Overall a larger trend can be seen where static programming models in the early 1990s are increasingly superceded by temporally disaggregate models in the late 1990s. This can be seen in the comparison between two static models (exergonomic and LP respectively), as applied to a district heating network in Italy [203] and to a district supply system in Germany [e.g. the decco model 204, 205], compared to the annually optimised design for the addition of solar heating systems to housing stock in Germany [206] (upgraded from a previous static operational optimisation model [207]). 


\subsection{Policy assessment}

So far we have seen a range of analyses from detailed studies of single technologies, to explorations of energy-efficient buildings and streets, through to the design and operation of district-wide energy systems. The final cluster continues this progression, representing studies of the whole city and how its energy performance might be shaped by policy decisions.

The 55 studies within this cluster rely less directly on computational models than in the other clusters. $55 \%$ of the papers might be described as empirical studies, examining the success or failure of past experiences. Examples include descriptions of a city's changing energy and pollution profile [208 211], case studies of what works and what doesn't in urban energy systems and sustainability [212 217], and observations on how key urban parameters, such as density, affect overall performance [218, 219]. Regression models are often used in this latter context to understand the impacts of, for example, consumer preferences [220, 221], price elasticities or other economic effects [222, 223], and general urban evolution [224]. Simulation and optimization are also used, primarily to assess the potential impacts of a policy change. Notable examples include the effect of urban form on energy use for water systems [225], predicting greenhouse-gas emissions for a Japanese city [226, 227], and the impact of transportation system changes [228 232 ].

Policy models are also common in retrofit applications, through MCDM (multiple criteria decision making) which is generally used for assessing decisions in light of multiple objectives [233]. One early study of this type used a static linear goal programming model to minimize pollutant emissions, energy system costs and energy imports for the planning of future energy systems in Delhi [234]. This is cited by Ramanathan [235] as they consider the effectiveness of five electricity generation options available to ur- 
ban households in Madras. Such studies need not be limited to considering the city as a whole and there are several examples of policy-style assessments of building-scale projects. For example, Rosenfeld [236] builds a decision tool for the process of renovating a 25 year-old dining hall in Israel while other building-level retrofit studies using MCDM were also found [49, 237, 238]. A recent paper uses MCDM to explore six scenarios in Limerick, Ireland, for retrofit measures that would impact on both domestic heating and electricity demand 239].

These analyses are typically performed at coarse temporal resolutions, with $56 \%$ of studies considering a static period of analysis and $29 \%$ looking at annual or decadal time spans. A mix of supply and demand-side issues are considered but these variables are often exogenously-specified; that is, in only about $34 \%$ of the studies do the model's seek to endogenously determine some aspect of the system's supply mix or demand structure. Integrated assessment models [e.g. 240, 241] are notable exceptions, simultaneously determining both supply and demand within an economic modelling framework. Bhattacharyya and Timilsina [242] provide a useful review of energy demand models for policy formulation in developing countries that touches on many of these points.

\subsection{Transportation and land use}

Upon reviewing these results, we felt that our search touched only lightly upon the large body of literature that might be termed "urban modelling" [243]. Within this field of transportation and land use research, integrated land-use-transport (LUT) models are most relevant to our review. These are large complex, generally econometric, model systems which seek to capture the major dynamics of urban processes such as land use change and transportation use. Within this body of research, until recently, energy had the 
limited definition of 'transport energy' with hardly any emphasis on stationary energy demands.

However, with the framework of these models being focused on human activity and land use patterns (especially with the recent developments in highly disaggregate agent and activity-based LUT models, for example ILUTE from Canada [244], CEMUS from Texas [245], SynCity from London [246]) they have great potential to produce resource demands that are disaggregate from a spatial, temporal and 'needs' perspective (i.e. heating, cooling, lighting, mobility). As described above, one of the key features of urban energy models is their treatment of resource demands. These are particularly important for the optimization-based integrated supply models detailed above, where these demands are typically exogenous to the model. The method commonly used to model energy demand in such models is to obtain energy consumption data, and use regression to devise correlations. A good example is seen in work by Brownsword et al. [247]. In contrast integrated Land Use-Transport (LUT) models, in particular the state-of-the-art agent-based microsimulation model systems, hold the potential to produce detailed energy and resource demands that are not only spatially and temporally disaggregate but also sensitive to a wide variety of scenarios, and are endogenous to the model. Moreover, in understanding urban energy consumption, it is important to take into account not only the short term factors such as where, when and how people participate in activities, but also the medium and long-term decisions made by individuals and households with respect to residential and workplace location, auto-ownership, labour force participation, and so on. LUT models provide the framework and means to undertake such a rigorous analysis [246, 248].

In the following section we first describe a typical integrated LUT model 
system and discuss the underlying conceptual framework of these models. This is followed by a more detailed discussion of the state of the art LUT model systems, drawing out their potential value to the urban energy modelling context.

\subsubsection{Background and overview}

Integrated land use-transport models were traditionally developed as a means of estimating travel demand in response to land use changes, and over the years have evolved to be rich descriptors of the activity and travel patterns of all the agents in the study area including households and individuals, businesses, real-estate developers and others. The land use components of such model systems describe medium to long-term urban processes such as household (re)location, work (re)location, real-estate development, business (re)location and automobile ownership, thus providing planners with a tool to forecast future land use layouts of urban areas. This is integrated with model components that predict the activity and travel patterns generated by the agents within the urban landscape; the transport flows created through these processes, in turn, feed back to the land use models guiding further real estate development, business and household relocation in response to the conditions on the transport networks.

Such integrated land use-transport model systems thus attempt to produce reliable and policy-sensitive travel demands by capturing the complex relationships between transport and land use in a system of descriptive models (for detailed reviews, see the works of Wegener [249, 250] and Hunt [251]). Furthermore, most operational land use transport model systems are loosely integrated with transport air quality and energy assessment models that translate the predicted transport flows into pollutant and fuel consumption estimates [see, for instance, 245, 252]. In fact, as Wegener [249] claims, these 
models are now being called integrated land use-transport and environment (LTE) model systems.

Figure 2 presents a conceptual framework that illustrates the kind of interactions that LUT model systems attempt to capture. Transport flows, price signals, building occupancies and consumptions typically form the links between land use and transport systems. A model that captures these interactions will be better able to predict: the changes in transport flows (and therefore fuel consumption) resulting from changes in urban layouts; energy consumption in buildings over space and time to accurately reflect the activity patterns underlying the occupancies; the direct effects of energy pricing on transport flows, as well as the indirect effects that result from corresponding changes in urban layouts.

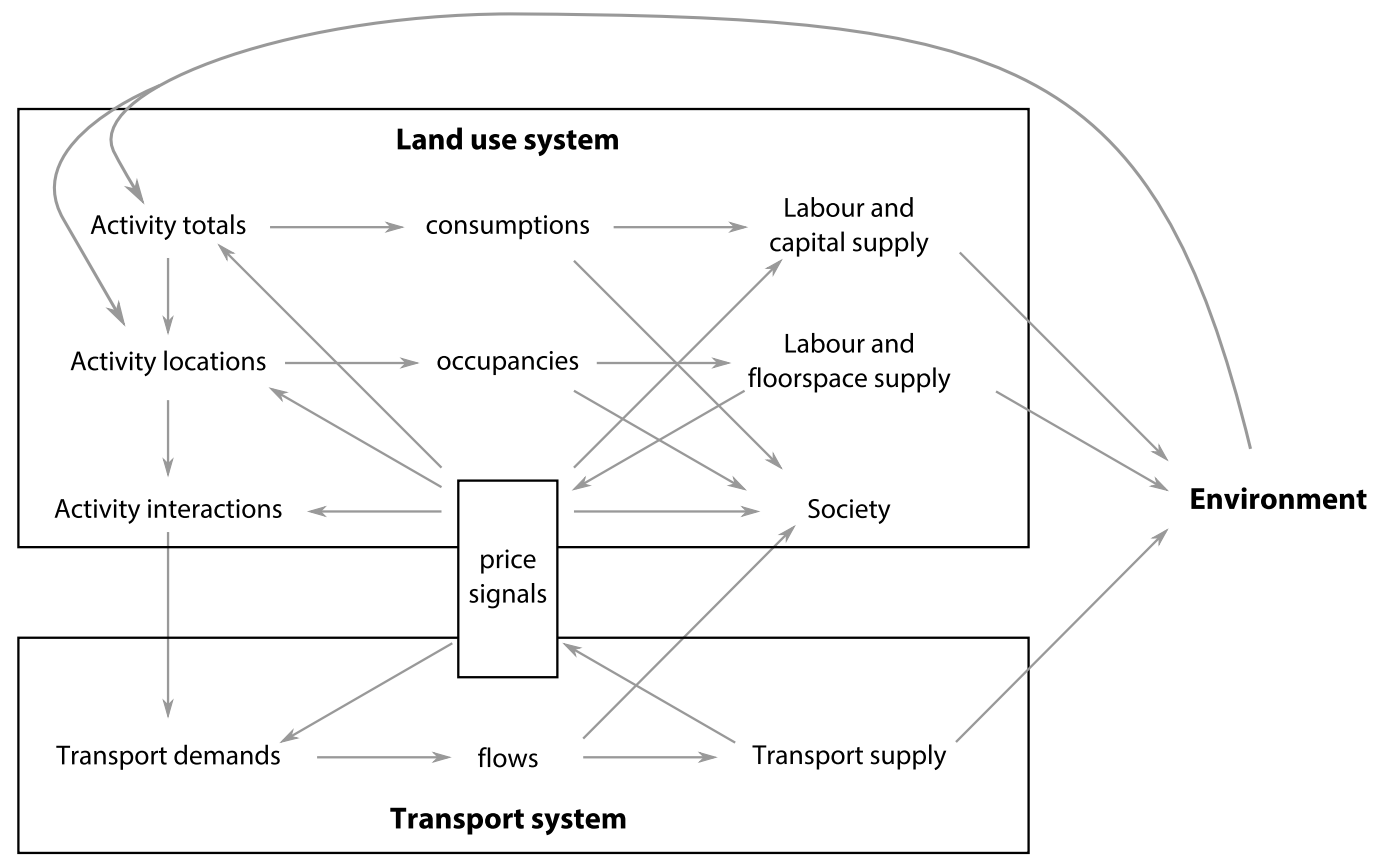

Figure 2: Conceptual Model of Land Use-Transport Systems 251.

However it is not until recently that operational LUT models have actually attempted to capture a number of these interactions in a behaviourally 
realistic manner. The earliest land use-transport models were essentially static models (see, for example, Lowry [253], LILT, the Leeds Integrated Transport package [254], DRAM/EMPAL by Putman [255], IMREL by Anderstig and Mattsson [256], MUSSA by Martinez [257]). These static models do not model market processes behaviourally and cannot realistically capture urban spatial processes and are therefore not very responsive to policy and scenario analyses. From the perspective of urban energy modelling then, these early models provide no additional benefits over the simpler, aggregate and exogenous demand vectors.

The next generation of LUT models were the general spatial equilibrium models such as MEPLAN [258] and TRANUS [259], which are typically also spatially aggregate models like the static models but with more closely integrated land-use and transport elements. Although these models capture the interactions between land use and transport systems systems more accurately, they are not entirely behaviourally realistic as they operate at high levels of spatial aggregation. Despite these limitations, TRANUS was one of the first LUT models that were used to analyse urban energy demand.

The third generation of LUT models, the agent-based micro-simulation models, combine the strengths of microsimulation and the disaggregate modelling of behaviour and land use processes (see, for example, DELTA by Simmonds [260], ILUTE by Miller et al. [244] and UrbanSim by Waddell [261], PRISM or the Puget Sound Regional Integrated Synthesis Model by Alberti and Waddell [262]). These are activity-based models with the individual (one person, household, firm, or any other agent in the urban system) as the unit of analysis. Hence, these models are intuitive in their formulation and capture the interactions between land-use and transport systems to the greatest extent possible. The key tool used in these models is micro-simulation, which 
provides a practical methodology to apply probabilistic models at the level of the individual. In turn, a key element in such micro-simulation models is the concept of a synthetic population of decision makers and the development of improved methods for the generation of such synthetic populations [for a review, see 263.

In the last few decades, several LUT models have been extended to include air quality, energy consumption and sustainability indicators. For instance, we now have PROPOLIS [264], which is an LUT model with energy and sustainability indicators; CEMUS [245] which is a very detailed model of individual travel behaviour and the energy and environmental implications thereof; ILUMASS [265] which combines land use, transport and the environment; I-PLACE3S or Internet-PLAnning for Community Energy, Economic and Environmental Sustainability [266] which is not a full-fledged integrated urban model but rather a GIS-based land-use mapping/scenario building platform. This is just a subset of the models available and for more detailed reviews of other currently operational urban models, please see Wegener [249, 250] and Kazuaki [267].

Another new urban energy model system being developed by a collaborative team led by MIT is iTEAM or Integrated Transport and Energy Activity-based Model [248]. As the name suggests iTEAM is focused on urban form, transport and energy demands working up from behaviour at the household/individual level and the form/organisational level. SynCity, being developed at the Energy Futures Lab in Imperial College London [246], is one of the very few urban energy model systems that integrates full-fledged and detailed supply and demand model components. 


\subsubsection{State-of-the-art LUT models as models of urban energy systems}

From the urban energy modelling perspective, therefore, state-of-the-art integrated land use-transport (LUT) models form a behaviourally realistic means of simulating consumption, and therefore resource demands. LUT model systems, as described above, are typically a suite of interconnected descriptive and normative models that can jointly predict the urban processes and activities. The embedded models are usually either micro-econometric and based on random utility maximisation principles [e.g. CEMDAP, 268], or based on decision heuristics (e.g. Albatross by Arentze and Timmermans [269], AMOS by Pendyala et al. [270]). Some models combine heuristic rules with econometric models [e.g. TASHA by 271].

The state-of-the-art LUT models, regardless of the underlying model types, are implemented as agent-based micro-simulation systems with the activities of all the agents in the study area being simulated. These models are also highly disaggregate with respect to time and space, some of the models operating on a continuous (second-by-second) time scale with parcelleve $]^{3}$ spatial detail. The flip side of such descriptively rich models is the quantity of data and computational time (effort) required to validate them for operational modelling, with some models taking up to 36 hours to simulate a single day's travel [272]. On the other hand, once operational, such models can be excellent test beds for a variety of policy scenarios, engineering and technological solutions. As integrated models, they effectively capture both direct and indirect effects of the scenarios of interest.

A key feature of the state-of-the-art LUT models is the underlying models

\footnotetext{
${ }^{3} \mathrm{~A}$ land parcel is an area of land that is uniquely defined for ownership or land use purposes. A parcel is therefore a fundamental cadastral unit: a piece of land which can be owned, sold, and developed.
} 
of individual and group behaviour. These models, unlike typical engineering models which are employed in the supply components of UES model systems, acknowledge the stochasticity of human behaviour and the intrinsic heterogeneity in this behaviour which results in both the same individual, and observationally-identical individuals, making very different choices.

The earliest models of agent-level behaviour focussed principally on predicting the choice of specific facets (such as mode or route or household location) of individual trips and tended to be deterministic in nature (typically assuming that behaviour was driven solely by considerations of cost or travel time minimisation). From the 1970s onwards these approaches were gradually replaced by models which, at the conceptual level, consider travel decisions explicitly as part of the broader context of an individual's programme of activity participation [273-275] and at a methodological level, treat decision making as a stochastic (rather than deterministic) process [276, 277].

The current state-of-the-art is represented by techniques based on the random utility formalism, which can accommodate a wide variety of decisionmaking contexts including both individual and group decisions, decisions regarding both discrete and continuous outcomes, static and dynamic decisions, decisions with single or multiple expressed outcomes, decisions made under uncertainty and those influenced by qualitative as well as quantitative factors. These methods can also be used as a means of integrating data both from real market outcomes ("revealed preference data") and data from hypothetical market studies ("stated preference data"). 


\section{Challenges}

From the survey of major approaches, it appears that current modelling practices only partially address the three key features of an urban energy system defined above. First, it was shown that studies often focus on specific aspects of energy use, with only the system design models looking at the full set of "combined processes" within an energy system, although often excluding the transport components of a city. Secondly, the studies often rely upon exogenous input data, for example, user-supplied electricity demands in the case of many system design models. Only a small number of integrated assessment models for policy considered both supply and demand endogenously. Finally, there does seem to be a good appreciation of local context in most models though as many papers examined specific cities (particularly in the policy assessment cluster).

Despite the diversity of practice highlighted by the review, a number of common challenges can be seen. The first is the complexity of the modelling domain. It was observed that a range of spatial and temporal scales are used but, particularly in older studies, the resolution and fidelity of the models can be limited by data availability and computational performance. For example, $44 \%$ of the 219 studies analysed district or coarser spatial scales and $58 \%$ dealt with annual or greater temporal resolutions. The second and related issue is data availability and quality. Many of the papers use modelling techniques that require large amounts of data such as econometric models of transportation or consumer behaviour, detailed GIS and 3D mapping of cities, and hourly profiles of energy consumption demands. Thirdly, the cluster analysis demonstrated the lack of model integration within the urban energy systems modelling community. The reasons for this are not covered by the scope of this paper, but it is clear that models are built by 
their developers for distinct purposes and unique audiences, and less effort appears to have been focused on creating larger integrated modelling systems. Such systems are arguably necessary to address the fourth challenge, policy relevance. Specific models may be able to answer narrowly-defined policy questions (e.g. building standards) but urban energy systems can be shaped by both direct and indirect effects of policy interventions, such as land-use planning restrictions on density which affect both building energy consumption and transportation options.

This section will now consider each of these four challenges in greater detail.

\subsection{Complexity}

Returning to Rosen's conceptualization of a model (that of a formal representation of a natural system with internally consistent rules), the models studied here are used to help understand a real-world system. The analytical process therefore involves two significant stages. First, in the "entailment" phase, a model's results must be internally interpreted. That is, the user must determine how the model has arrived at a result and whether this is consistent with the model's formulation and implementation. If this is acceptable, then the second step is to "decode" these model results and interpret them in light of the real system.

Both of these processes are plagued by the complexity of urban energy systems. For example, the system design cluster arguably represents some of the most complex models identified by the review. Optimization techniques may attempt to incorporate some of these complexities with a technique like multi-objective optimization [278] or sensitivity analysis [177]. Yet all models tread a fine line between tractibility and model performance. For example, modern models can take between several days [279] to several hours [192] 
and shorter, dependent on the method, scope and computing power at play. Related to this, over-simplifying or over-detailing a model may obstruct the true value of the output from the model's internal relationships.

The levels of complexity in models are countered by the fact that the core assumptions embedded in a model's architecture will determine how accurate a model will be. Less complexity generally means more assumptions, but if the core assumptions are invalid, then the methodology is of little or no importance [280]. Unfortunately, the assumptions included in models are often hidden from view. The audience and purpose for which a model is built is also of importance, yet these are often left unmentioned in papers. For example, a model built for aiding the investment decisions of a local government is likely to be quite different to that of a model built for the engineer in charge of a community scale CHP plant [e.g 186, 206]. One way to challenge the untested assumptions is the use of 'backcasting' to ensure the model can forecast the past accurately [281].

A specific challenge involves integrating the LUT and LTE model systems. These are essentially systems of models predicting different quantities (type of activity an individual undertakes in a day, time of day of activity participation, choice of technology in undertaking activity etc) that are linked together. Relevant issues therefore include the validity of the sequentiality in implementing the sub-models, the econometric issues associated with microsimulation, and quantification of the flow of uncertainty through the model system. The current state of the practice is to use the microsimulation model system as a test bed to undertake rigorous sensitivity analyses. However, this is an area that clearly needs further research as it is a relatively small body of research compared to the proliferation of such complex model systems. 


\subsection{Data availability and uncertainty}

All models rely on some form of data and without good quality information, the user faces the perennial problem of garbage-in garbage-out. There are two major issues: data availability and data uncertainty.

Acquiring good quality data for urban energy modelling faces at least one intrinsic challenge, namely that cities are open systems and defining the boundaries of the urban energy system can be difficult. The studies we reviewed primarily use data gathered from administrative or district boundaries and only a few include lifecycle assessments that extend beyond the city boundaries. This creates a challenge for the modeller, who must assess the quality of the available data source and determine whether or not it is sufficient to answer their research question. In developing countries in particular, acquiring any urban energy statistics can be difficult although there were some exceptions within the data set including the energy consumption of bakeries in Nigeria [282, gasoline consumption in Mexico [231], and industrial combustion in Brazil [211]. Improving the availability of data on developed country cities is particularly important because the UN and IEA forecast that, in the coming decades, urban population and energy service demand will grow most quickly in these regions.

There are some technique-specific data availability issues. For example, LUT models are essentially descriptive models that need data in order to be calibrated prior to implementation. As the models get more complex in terms of integrating land use, transport and the environment, operating at the level of the decision-making agent (e.g. individuals, households, businesses), assessing detailed spatial and temporal scales - the corresponding data needs grow very quickly. However this need not be a stumbling block in the development of such models as researchers have explored and exploited 
mathematical approaches of pooling data from different sources [246].

The second major issue is data uncertainty. Observed data may be uncertain due to measurement error, the need to use proxy data sources or calculation adjustments (e.g. for downscaling national level data to a city scale on a per-capita basis). Ideally such parameters would be expressed along with their uncertainty but the majority of papers surveyed did not explicitly describe methods of dealing with the uncertainty of parameters. Deterministic optimisation models in particular are guilty of this, whereas stochastic algorithms such as genetic algorithms do provide a probabilistic solution set. Other relevant optimization techniques include two-stage stochastic programming, parametric programming, fuzzy programming, chance constraint programming, robust optimization techniques and conditional value-at-risk [283]. More generally there is a need to describe both the uncertainty of collected input data and the way in which this feeds into the modelling methodology.

\subsection{Model integration}

With the exception of two integrated assessment models [240, 241], there appears to have been very few attempts to integrate models that span across multiple sectors or disciplines. Depending on the goal of the analysis, this may not be an issue. However if urban energy systems modellers are to tackle the complexity of their domain, then model integration is a sensible strategy.

Integration raises both practical and theoretical questions about how models might fit together. As a simple example of the potential interactions, consider some of the urban heat island effect papers identified earlier. In these cases, a building model may be able to determine indoor climate given orientation, solar exposure, and so on. A technology model might then determine the best air conditioning system for the building, but the 
rejected heat from this air conditioner would of course be rejected into the environment thus changing the building's thermal performance (particularly if groups of buildings are located in close proximity).

A more significant example where model integration seems to be missing is between urban land use and transportation models and energy system models as mentioned in section 3.6. There has been work on linking transport models and impact assessment models (e.g. for local air quality [284]), and by simulating land use changes and the way in which individuals use urban facilities, it should be possible to get a better understanding of energy service demands in time and space [246]. Essentially, the development of urban energy system models with detailed LUT-based demand components involves the integration of two different modelling paradigms: descriptive models of human behaviour combined with normative models of urban supply systems. This is an inherently challenging task, which questions the concept of an equilibrium state.

\subsection{Policy relevance}

The three challenges of complexity, data availability and uncertainty, and model integration must all be interpreted in light of a model's purpose. A tool that is used to design a solar hot water heating system, for example, may find it easier to acquire sufficient data for the generation of useful results than a more complex system design model. However from a policy perspective, i.e. for decision-makers looking to improve the performance of the overall urban energy system, many of the models identified by this review were applied to a relatively narrow set of policy problems - evaluating transport pricing policies, estimating the impacts of new low-energy technologies, examining the environmental impacts of demographic evolution, evaluating the social equity of a specific policy, and so on. This is limiting as the narrow perspective often 
fails to account for indirect effects of policies on the urban system. It also fails to account for the conflicting effects of different policies. For instance, congestion charging intended to reduce traffic congestion and emissions in the city centre could lead to land use changes with businesses relocating outside the charging zone, which in turn leads to an increase in travel distances and therefore more emissions. As urban systems face tighter integration through developments such as electric mobility, it becomes increasingly important to account for the combined effects of policies (transport and energy policies in the case of electric mobility). Indeed in the face of the complex problems faced by urban areas and in light of the tightly integrated sub-systems in urban areas, probably the most difficult challenge faced by UES models is to produce reliable policy-sensitive and meaningful answers.

An important issue perhaps is to define the analysis goal more clearly. In other words, the papers studied here did not always make it clear what an ideal urban energy system might look like (although common themes like lower greenhouse gas emissions were apparent) and, more problematically, did not discuss the links between innovations in the energy system and other areas of urban policy. For example, when Edison sold electricity as a better alternative to kerosene to the Wall Street firms of Lower Manhattan, he did so on the basis of its lower systematic cost and not its luminous efficiency [285]. Similarly, most retrofit projects are not designed with the improvement of energy systems as their primary aim. Rather this is usually a by-product of property development (i.e. regeneration) or forced replacement of an obsolescent or broken component.

The challenge for urban energy system modellers, then, is to create tools that explicitly capture some of the linkages between energy systems and other aspects of urban policy. At the very least, modellers should be aware of these 
connections so that modelling results can be presented in a policy-relevant fashion with caveats acknowledged.

\section{Opportunities}

Creating an integrated policy-responsive urban energy systems model, that captures parameter uncertainty and performs in an acceptable manner, is a daunting challenge. However there are a number of opportunities that offer promise. Many of the following techniques are well-established in other disciplines but have yet not been widely used in urban energy systems modelling. We therefore wish to highlight three themes as fertile ground for experimentation and disciplinary learning.

\subsection{Sensitivity analysis and cloud computing}

As shown above, urban energy system models are often complex, consisting of large numbers of input parameters whose "true" values may be uncertain and that interact in non-linear ways. Returning to Rosen's 1991 definition of a model, this creates difficulty in both the entailment and decoding processes. Entailment refers to the self-consistency of the formalized model system. For a complex model, the difficulty is that drawing inferences from a model's output can be obstructed by the multiple interactions within the model. That is, it may not be possible to intuitively attribute a given change in the model's output to a change in the model's input. Similarly, once an inference is made from the formal system, decoding its meaning back to the natural system is complicated by questions of whether the model sufficiently captured the salient aspects of that system. In this section, we will concern ourselves primarily with the entailment/inference process, i.e. how can we fully understand the internal behaviour of complex integrated 
urban energy system models? How can we reassure ourselves that the conclusions drawn from such models are robust under a range of assumptions and scenarios?

\subsubsection{Methodological issues: uncertainty and sensitivity analysis}

From a methodological perspective, one of the most basic ways of studying complex models is uncertainty analysis, that of quantifying uncertainty in a model's output [286]. To perform this assessment, each of the model's input parameters is described as being drawn from a statistical distribution in order to capture the uncertainty in the parameter's true value. Vectors of input parameters are then drawn from these distributions and a number of independent model runs performed, using values from the randomly drawn vectors of input variables. The variability of model's output variables can then be summarized with descriptive statistics, graphical plots, and so on.

In contrast, sensitivity analysis can be defined as "the study of how uncertainty in the output of a model (numerical or otherwise) can be apportioned to different sources of uncertainty in the model input" [286, p. 1]. This is a more powerful technique as it allows the modeller to determine which of the input variables has the greatest affect on the model's output, both on its own and through interactions with other variables. There are a number of different sensitivity analysis approaches, or settings, depending on the analyst's goal: factor prioritization, to determine which input when fixed to its true value leads the greatest reduction in output variability; factor fixing, to determine which inputs make no significant contribution to the variance of the output regardless of their value; variance cutting, to adjust model output below a given variability threshold, e.g. for risk analysis applications; and factor mapping, to study which model inputs lead to certain model outputs [286]. These methods rely on variance-based calculations, and consequently 
depend on multiple model runs with different input values (as in uncertainty analysis). The number of model runs will depend on the analysis technique being used and the number of input parameters in the model but it can range from tens to thousands of model runs.

These two techniques have been applied in a range of disciplines. Hall et al. [287], for example, demonstrate sensitivity analysis techniques for hydraulic engineering models (both simple and more complex models), concluding that these variance-based methods are helpful for capturing the nonlinear and interaction effects within complex models. de Rocquigny et al. [288] provide a number of examples from oil exploration, radioactive waste safety management, financial models, geotechnics, component fatigue, and many other areas. From our review of models, three of the 219 studies explicitly mentioned uncertainty or sensitivity analysis and all were from the "systems design" cluster. Two of these cases considered optimization under uncertainty, that is formulating on optimization problem to consider the uncertainty endogenously; Lin and Huang [289] did so with interval-parameter programming and Huang et al. [290] used stochastic dynamic programming. These formulations can be computationally very intensive, limiting the size of problems that can be practically handled. An alternative approach is that of Lozano et al. [291, who performed a more traditional one-at-a-time sensitivity analysis (i.e. varying the value of one parameter while holding others constant) to assess the impact of finance assumptions and natural gas prices in a MILP model of an energy supply system. However none of the three papers used the variance-based sensitivity methods described above, which enable the description of interaction effects and attribution of output variability. 


\subsubsection{Practical considerations: cloud computing}

This suggests that urban energy system models do not use best practice methods in uncertainty and sensitivity analysis. If the complexity of these models is to be better understood, then model developers should experiment with these techniques to see how their models perform under a range of uncertainty. But as described above, these methods may require thousands of Monte Carlo simulations and, for complex models, this can be prohibitively time-consuming. How then can these analyses be performed in a timely manner?

One of the most promising opportunities is "cloud computing", which can be broadly defined as the delivery of software services over the Internet and the behind-the-scenes hardware and software systems that provide them [292]. The idea of "software as a service", or computing as a utility like water or energy, is not new and can be traced back to 1969 and the early days of the internet [293]. Indeed before the rise of personal computing, which provided small-scale desktop hardware and software systems, computing infrastructure largely consisted of centralized mainframes accessed via time-sharing arrangements and terminals [294]. However the recent construction of largescale data centres have enabled three new features of cloud computing: the ability to requisition almost unlimited computing resources on demand, the ability to avoid up-front cost commitments, and the ability to pay for the use of computing resources at short notice and as necessary. These features have enabled decreases in the cost of electricity, network bandwidth, software and hardware by a factor of 5 to 7 , meaning that cloud computing is now a practical and financially-attractive option for many commercial entities and researchers [292].

In the context of sensitivity and uncertainty analysis, one of the main ad- 
vantages is "cost associativity". These techniques require hundreds or thousands of model runs, each of which can be run independently before being combined for the final analysis. With cloud computing, a user who purchases 1000 computer-hours can simply perform 1000 one-hour simulations simultaneously rather than waiting over a month for a single computer to perform the same task. Another benefit is that computationally-expensive calculations, such as integer programming for system design models, can be performed on the cloud freeing up desktop computing resources for other tasks [292]. For academic researchers, these features may sound similar to other highperformance computing paradigms, such as cluster or grid computing (see [293] for a detailed comparison of these approaches). Cloud computing offers several further advantages, particularly in easing the administrative overhead of such systems, and initiatives like the Nimbus Project ${ }^{4}$ have demonstrated how cloud computing can be applied in a range of academic disciplines such as high-energy physics, computer science, bioinformatics, and economics [295].

Looking forward, Armbrust et al. 292] identify 10 obstacles and opportunities for the adoption of cloud computing including: availability of service, data lock-in, data confidentiality and auditability, data transfer bottlenecks, performance unpredictability, scalable storage, debugging large-scale distributed systems, configuration for efficient scaling, reputation fate sharing, and software licensing. These represent a mix of technical and administrative obstacles, but in the context of urban energy system modelling, some of the listed items are of less concern. For example, at present urban energy system models are primarily used for offline analyses; that is, they are run infrequently to provide guidance to engineers, scientists, and policy

\footnotetext{
${ }^{4}$ http://www.nimbusproject.org
} 
makers, but they are less frequently used to make minute-to-minute operational decisions. This means that service availability, rapid scaling, and unpredictability of performance may be acceptable disadvantages, particularly if higher standards incur cost premiums. On the other hand, building and running large-scale models that use specialist codes (e.g. commercial optimization solvers) may encounter problems with debugging and software licensing.

Cloud computing therefore offers a promising, but not trouble-free, option for the analysis of complex urban energy system models using Monte Carlo and sensitivity analysis techniques. These tools provide strong theoretical and practical platforms for assessing parameter uncertainty and interaction effects and urban energy researchers should begin to experiment with these technologies. Ultimately as these tools become more mature, urban energy system models could be made available as cloud applications (i.e. shifting from the "infrastructure as a service" model to "software as a service"), potentially providing access to engineers, policy makers, and other practitioners in the field.

\subsection{Data collection and integration}

A common challenge described in Section 4 is that of data availability (both quantity and quality). This is particularly true in the more complex system design and LUT models above, where data hungry models require vast datasets for initial calibration. Urban data is often recorded at different times by different people, and may need to be adapted from other sources (for example, scaling-up household survey data or scaling-down national energy statistics). Furthermore there is a particular lack of data in developing countries' cities. These issues suggest that there could be benefits from improving data collection standards and data sharing amongst researchers. Three spe- 
cific opportunities discussed here are the definition of a standard vocabulary for urban energy systems, the development of a shared ontology for the domain of urban energy models, and a common repository for historical urban data.

Firstly, a standard set of terms for urban energy would be useful as a transparent basis of comparison between modelling methods and case studies. Agreed definitions amongst researchers are used in other fields, for example the glossary used by the Intergovernmental Panel on Climate Change for their assessment report on mitigation strategies [296]. In the urban energy context, the key issues are likely to be the definition of urban and energy systems boundaries which could be of benefit for comparative studies of modelling methodologies. The definition of urban energy systems that we have proposed above provides a starting point for such a discussion, as it highlights the range of issues that should be considered.

Secondly, a set of standardised definitions of urban energy models could be formalised into a shared and structured ontology, for example through the open-source software Protégé 5 , An ontology is defined as a formal "explicit specification of a shared conceptualisation" [297], and ontologies are widely used in information science to describe the relations between defined objects within a particular domain, and the properties of these objects. For instance, the SynCity project at Imperial College employs an ontology to describe the objects, processes and relationships inherent in the combined processes of cities. As such, "electricity" is defined as an instance of the resource class, which has assigned properties, such as the cost of import and unit of measure. The process classes, along with their instances (e.g. an electric heater), are

\footnotetext{
$\sqrt[5]{\text { http://protege.stanford.edu/ }}$
} 
then related to the electricity resource by the use of electricity units [246].

There are many potential benefits of setting up an international ontology for urban energy models, including increased dialogue, transparency and standardised bases for comparative research. However the large investments in both time and money that researchers expend in creating their work environments are a large barrier to adoption of new techniques. It will also be necessary to involve senior researchers in the field, as their tacit experience will be invaluable in assigning the relevant relationships between objects [298]. A number of examples of previous projects have been attempted, including the Digital Government Research Center's Energy Data Collection system, where an ontology was created to standardize data types and enable sharing of U.S. federal and state level monthly energy statistics. This ontology described the relations between, for example, product type (e.g. unleaded gasoline), property measured (e.g. price, volume), area of the measure (e.g. USA, California) and the unit of measure [299]. More recent research has compared ontologies built for different methods of agent based modelling of urban energy systems, and found them to be complementary [300]. Moreover, a recent survey of 50 energy modellers determined that the majority of modellers build their own tools and models, but only half use some form of shared ontology [301].

Finally in parallel with the suggestions above, there is a place for the construction of a centralised repository for cities' energy related data. This would be useful in organizing existing data sources and providing a natural home for new data emerging from the so-called "data deluge" of pervasive sensors, mobile phones, and so on [302]. Storage of energy related data is already employed by many organisations, yet is largely on a national scale [303 305] although some countries provide much more detailed data at a 
neighbourhood level [306]. The consolidation of this data, along with the identification of key indicators, could be helpful in providing robust analyses of urban energy systems. This would be particularly useful for data-scarce developing world cities. An excellent example of how this can be done in an interactive open manner is Enipedia, a semantic wiki that enables users to access a wide range of energy system data and easily manipulate for their own research purposes 6 .

The goal of these activities should therefore be to make data collection, organization and sharing easier so that researchers can focus on analysis.

\subsection{Model integration via activity-based modelling}

Activity-based models of land use and transport processes present a significant new opportunity for the development of bottom-up activity-based models of resource and energy demand. As described in Section 3.6.2, the current state-of-the-art in integrated land use-transport models can predict travel and activity patterns of all the agents in the study area at high levels of spatial and temporal resolution, in a behaviourally realistic and policy sensitive manner. The extension of such demand models to all resources (e.g. heating, electricity, transport fuel and others) and their integration with integrated urban supply networks is therefore one of the most promising emerging opportunities in the field of urban energy systems modelling.

An integrated bottom-up and disaggregate model of urban demand and supply vectors would have several attractive qualities, such as the ability to predict resource demands at high spatial and temporal resolutions, to the extent of being able to produce building-by-building resource needs by the second; the ability to predict resource demands along different dimensions

\footnotetext{
${ }^{6}$ http://enipedia.tudelft.nl/wiki/Enipedia
} 
while at the same time retaining the dependencies and links between these resource demands; sensitivity to a variety of policy scenarios and the ability to capture both the direct and indirect effects of policies on resource demands. Activity-based integrated urban energy system models could therefore form an effective test-bed for new scenarios and technological solutions.

\subsubsection{Strengths of integrated activity-based urban energy system models}

The strengths of such a model are attributable primarily to two factors. First, the activity-based paradigm ensures a behavioural approach to predicting resource demands that acknowledges their derived nature. In other words, resource demands arise as a result of individuals performing activities and the models consequently produce reliable and policy-sensitive forecasts that retain the links between different demand vectors. Second, the agentbased disaggregate approach provides high resolution detail, which serves as an effective input to integrated supply models.

These attributes of activity-based models are owed to the significant developments in micro-econometric and simulation methods. An agent-based micro-simulation model of urban energy systems supports not only the simulation of the infrastructure networks but also the behaviour, activities and consequent resource demands of every entity in the study area by the second. Moreover, econometric advances in behavioural modelling that have occurred over the last few decades have enabled the development of disaggregate behavioural models that predict highly heterogeneous behaviours of individuals such as loyalty, variety-seeking, learning, spatial cognition, socially constrained preferences and norms, and so on. 


\subsubsection{Challenges in developing integrated activity-based urban energy system}

models

The primary challenges in developing an integrated activity-based model of urban energy systems are the computational requirements and data needs. The development and calibration of such extensive integrated model systems depends on the availability of a variety of different kinds of data, which is typically not available from a single source. Also the implementation of these model systems accordingly requires extensive data handling capabilities as well as computational efficiency. However, in an increasingly digital world, we have many new potential sources of data such as GSM and GPS traces from mobile phones that mitigate the challenge posed by the data requirements, just as the development of parallel computing technologies and cloud storage serve to mitigate the computational challenge.

While these are challenges that the urban and transport planning community have faced for a long time, a new challenge posed by the integration of urban demand and supply models is the interesting new interface that is created between the descriptive demand models and the normative supply models. Such an interface has been traditionally dealt with through equilibrium-seeking feedback processes, though some behavioural economists argue that most complex systems (such as urban energy systems) are never in equilibrium. The development of integrated and activity-based urban energy model systems therefore open up interesting questions as well as opportunities.

Technically, the development of these models will be aided by some of the opportunities identified above. In particular, computational advances (e.g. parallelisation, more efficient microsimulation models, and more powerful computers), as well as the increased usage of cloud computing and ontologies 
as described above, will be vital if the capabilities of these models are to be expanded while maintaining their usability. Model development efforts are likely to focus on improved behavioural models, as descriptions of the decision-making behaviour of individual agents (e.g. travellers, developers, employers) underpin these tools. Developments in the technologies available for modelling these agent-level behaviours serve as a strong driving and enabling force in the development of behaviourally-realistic and policy-sensitive resource demand prediction models.

\subsubsection{Value of integrated activity-based UES models}

Ultimately, however, the value of developing such integrated models lies in the application. What are the needs fulfilled by models of urban energy systems? These systems are typically developed: (a) to analyse the impacts of various demographic scenarios (such as aging and migration patterns); (b) to test and evaluate different policy measures and baskets of policies (such as fuel taxation or fiscal incentives for energy efficient consumer products such as hybrid electric vehicles); (c) to test technological and systems level solutions (such as CHP, centralised versus decentralised energy supply networks, renewable energy sources and associated energy storage) and (d) to identify opportunities for energy efficiency (such as through retrofitting or more closely integrated supply networks). Integrated urban energy system model systems can thus potentially support policy-makers, city planners, entrepreneurs as well as businesses such as energy and resource suppliers, and technology manufacturers.

\section{Conclusions}

As is evident from the large and diverse body of literature highlighted here, urban energy consumption is of growing interest and models of urban 
energy systems are a key tool in assessing better designs, new policies, and related technologies. Over the last few decades there has been a deluge of models with a variety of formulations and applications, and a wide temporal and spatial scale. However, there is no resource out there that helps understand and make sense of this vast body of literature, no piece of work that brings to light the full scope of the activity in this area. That is the gap we attempt to fill with this paper, by providing a comprehensive review of the literature in urban energy systems modelling.

We first presented a definition of urban energy systems, as "the combined processes of acquiring and using energy to satisfy the energy service demands of a given urban area". This set the context and scope for a review of 219 papers, covering five distinct areas of practice. On reviewing these papers it was noted that integrated land use-transport (LUT) modelling, although highly relevant to urban energy systems, was missing from the search results and so a supplementary review of this area was conducted.

The field of urban energy systems modelling clearly faces a number of challenges, including technical obstacles related to the complexity of the models and data uncertainty, and audience-oriented issues concerning model integration and policy relevance. To some extent, we believe these can be alleviated by opportunities in methods and technology including new data sources such as GPS/GSM signal traces, sensitivity analysis and cloud computing, and activity-based modelling. Although these are technical innovations, we believe they will also improve the policy relevance of work in this area by capturing more policy levers, explicitly addressing questions of uncertainty, and by defining standards for consistent and comparable data.

Overall then, the future of urban energy systems modelling appears to be the use of activity and agent-based modelling methods in conjunction with 
improved data standards and computational advances to estimate spatially and temporally disaggregated resource demands within an integrated model of urban energy supply. Such a model would capture the complexity inherent in urban areas today and would enable the analysis of baskets of policies and solutions that cut across traditionally independent but increasingly interrelated sectors such as transport, electricity, heating and even other urban resource services such as water supply.

Urban energy system modelling unarguably has a great deal of potential and faces numerous other challenges not explicitly addressed here, such as the challenges of modelling developing economies. However this paper has tried to collate a diverse body of practice into a recognizable field, one to which researchers and practitioners can contribute and develop further.

\section{Acknowledgments}

The financial support of BP via the Urban Energy Systems project at Imperial College London (www.imperial.ac.uk/urbanenergysystems) is gratefully acknowledged.

\section{References}

[1] UN, . World urbanization prospects: the 2007 revision population database. 2008. URL http://esa.un.org/unup/.

[2] World Bank, . World Development Report 2009: Reshaping Economic Geography, Part 1. Tech. Rep.; World Bank; Washington, DC; 2008. URL http: //www . worldbank . org/wdr2009.

[3] Kotkin, J.. The city: a global history. London: Weidenfeld \& Nicolson; 2005. ISBN 0297646850 (hbk.). 
[4] McGranahan, G., Marcotullio, P., Bai, X., Balk, D., Braga, T., Douglas, I., et al. Urban systems. vol. 1. Washington: Island Press; 2005, p. 795-825. URL http://www. maweb.org/documents/document. 296. aspx.pdf.

[5] IEA, . World Energy Outlook. Paris: International Energy Agency; 2008.

[6] Jaccard, M.K.. Sustainable Fossil Fuels: The Unusual Suspect in the Quest for Clean and Enduring Energy. Cambridge: Cambridge University Press; 2005.

[7] Kennedy, C., Steinberger, J., Gasson, B., Hansen, Y., Hillman, T., Havránek, M., et al. Methodology for inventorying greenhouse gas emissions from global cities. Energy Policy 2009;38(9):48284837. doi: \bibinfo\{doi\}\{10.1016/j.enpol.2009.08.050\}. URL http: //linkinghub.elsevier.com/retrieve/pii/S0301421509006387.

[8] Foresight Sustainable Energy Management and the Built Environment Project, . Final Project Report. Tech. Rep.; Government Office for Science; London; 2008. URL http://www.bis. gov.uk/foresight/our-work/projects/published-projects/ sustainable-energy-management-and-the-built-environment.

[9] Hughes, T.. Networks of Power Electrification in Western Society, 1880-1930. Baltimore: Johns Hopkins University Press; 1983.

[10] Buettner, T. An overview of World Urbanization Prospects. In: Urbanization, Development Pathways and Carbon Implications workshop. Tsukuba; 2007,URL http://www.gcp-urcm.org/files/ A20070328/buettner.pdf. 
[11] Schulz, N.B.. The direct material inputs into Singapore's development. Journal of Industrial Ecology 2007;11(2).

[12] Ramaswami, A., Chavez, A., Ewing-Thiel, J., Reeve, K.E.. Two approaches to greenhouse gas emissions foot-printing at the city scale. Environmental science \& technology 2011;45(10):4205-6. doi: \bibinfo\{doi\}\{10.1021/es201166n\}. URL http://www.ncbi.nlm.nih. gov/pubmed/21520902.

[13] Arup, . Climate Action in Megacities: C40 Cities Baseline and Opportunities. Tech. Rep. June; Arup; London; 2011.

[14] Rosen, R.. Life Itself. Columbia University Press; 1991.

[15] R Development Core Team, . R: A Language and Environment for Statistical Computing. 2010. URL http://www.r-project.org.

[16] Maechler, M., Rousseeuw, P., Struyf, A., Hubert, M.. Cluster Analysis Basics and Extensions. 2005.

[17] Shiau, C.S.N., Kaushal, N., Hendrickson, C.T., Peterson, S.B., Whitacre, J.F., Michalek, J.J.. Optimal Plug-In Hybrid Electric Vehicle Design and Allocation for Minimum Life Cycle Cost, Petroleum Consumption, and Greenhouse Gas Emissions. Journal of Mechanical Design 2010;132(9):091013. doi: \bibinfo\{doi\}\{10. 1115/1.4002194\}. URL http://link.aip.org/link/JMDEDB/v132/ i9/p091013/s1\&Agg=doi.

[18] Eriksson, A., Jacobson, B.. Modular modelling and simulation tool for evaluation of powertrain performance. International Journal of Vehicle Design 1999;21(2/3):175. doi: \bibinfo\{doi\}\{10.1504/IJVD.1999. 005575\}. URL http://www . inderscience. com/link . php?id=5575. 
[19] Rincón, J.. Experimental and numerical evaluation of a solar passive cooling system under hot and humid climatic conditions. Solar Energy 2001;71(1):71-80. doi: \bibinfo\{doi\}\{10.1016/S0038-092X(01) 00010-X\}. URL http://linkinghub.elsevier.com/retrieve/pii/ S0038092X0100010X.

[20] Kaewniyompanit, S., Sugihara, H., Tsuji, K.. An Evaluating Model of Photovoltaic Power Output Variations for an Energy System Planning in an Urban Area. IEEJ Transactions on Electrical and Electronic Engineering 2009;4(4):534-544. doi: bibinfo\{doi $\}\{10.1002 /$ tee.20440\}. URL http://doi.wiley.com/10.1002/tee.20440.

[21] Kaewniyompanit, S., Sugihara, H., Tsuji, K., Funabashi, T., Okuno, Y., Hayashi, T.. Maximum potential of PV installation based on an energy system planning model considering a distribution voltage constraint. IEEJ Transactions on Electrical and Electronic Engineering 2009;4(2):257-268. doi: \bibinfo $\{$ doi $\}\{10.1002 /$ tee.20310 $\}$. URL http: //doi.wiley.com/10.1002/tee.20310.

[22] Celik, A.N., Muneer, T., Clarke, P.. An investigation into micro wind energy systems for their utilization in urban areas and their life cycle assessment. Proceedings of the Institution of Mechanical Engineers, Part A: Journal of Power and Energy 2007;221(8):1107-1117. doi: \bibinfo\{doi $\}\{10$. 1243/09576509JPE452\}. URL http://journals .pepublishing.com/ openurl . asp?genre=article\&id=doi:10 . 1243/09576509JPE452.

[23] Allen, S.R., Hammond, G.P., McManus, M.C.. Energy analysis and environmental life cycle assessment of a micro-wind turbine. 
Proceedings of the Institution of Mechanical Engineers, Part A: Journal of Power and Energy 2008;222(7):669-684. doi: \bibinfo\{doi $\}\{10$. 1243/09576509JPE538\}. URL http://journals . pepublishing.com/ openurl . asp?genre=article\&id=doi :10 . 1243/09576509JPE538.

[24] D'Alessandro, V., Montelpare, S., Ricci, R., Secchiaroli, A.. Unsteady Aerodynamics of a Savonius wind rotor: a new computational approach for the simulation of energy performance. Energy 2010;35(8):3349-3363. doi: \bibinfo $\{$ doi $\}\{10.1016 /$ j.energy.2010. 04.021\}. URL http://linkinghub.elsevier.com/retrieve/pii/ S0360544210002136.

[25] Ahmed, A.S.. Wind energy as a potential generation source at Ras Benas, Egypt. Renewable and Sustainable Energy Reviews 2010;14(8):2167-2173. doi: \bibinfo\{doi\}\{10.1016/j.rser.2010. 03.006\}. URL http://linkinghub.elsevier.com/retrieve/pii/ S1364032110000614.

[26] Grant, A., Johnstone, C., Kelly, N.. Urban wind energy conversion: The potential of ducted turbines. Renewable Energy 2008;33(6):11571163. doi: \bibinfo\{doi $\}\{10.1016 /$ j.renene.2007.08.005\}. URL http: //linkinghub.elsevier.com/retrieve/pii/S096014810700256X.

[27] Muller, G., Jentsch, M., Stoddart, E.. Vertical axis resistance type wind turbines for use in buildings. Renewable Energy 2009;34(5):14071412. doi: \bibinfo\{doi $\{10.1016 /$ j.renene.2008.10.008\}. URL http: //linkinghub.elsevier.com/retrieve/pii/S0960148108003510.

[28] Hill, N., Dominy, R., Ingram, G., Dominy, J.. Darrieus turbines: the physics of self-starting. Proceedings of 
the Institution of Mechanical Engineers, Part A: Journal of Power and Energy 2009;223(1):21-29. doi: \bibinfo\{doi\}\{10.1243/ 09576509JPE615\}. URL http://journals.pepublishing.com/ openurl . asp?genre=article\&id=doi:10 . 1243/09576509JPE615.

[29] Ayoubi, M., Ghaddar, N., Ghali, K.. Energy consumption of Solar-assisted Desiccant Dehumidification Air Conditioning System in Beirut. Kuwait Journal of Science and Engineering 2007;34(1B):107122.

[30] Jaefarzadeh, M.. THERMAL BEHAVIOR OF A LARGE SALINITYGRADIENT SOLAR POND IN THE CITY OF MASHHAD. IRANIAN JOURNAL OF SCIENCE AND TECHNOLOGY TRANSACTION B-ENGINEERING 2005;29(B2):219-229.

[31] Vaziri, L., Kellier, L.. Sustainability Is Possible for an Urban HighRise: Florida Atlantic University Solar Roof Case Study. Journal of Green Building 2009;4(4):33-38. doi:\bibinfo\{doi\}\{10.3992/jgb.4. 4.33\}. URL http://www . atypon-link . com/CPUB/doi/abs/10.3992/ jgb.4.4.33.

[32] Arboit, M., Diblasi, A., Fernández Llano, J., de Rosa, C.. Assessing the solar potential of low-density urban environments in Andean cities with desert climates: The case of the city of Mendoza, in Argentina. Renewable Energy 2008;33(8):1733-1748. doi: \bibinfo\{doi\} \{10.1016/j.renene.2007.11.007\}. URL http://linkinghub.elsevier. com/retrieve/pii/S0960148107003680.

[33] Moghadam, H., Tabrizi, F.F., Sharak, A.Z.. Optimization of solar flat collector inclination. Desalination 2011;265(1-3):107- 
111. doi: $\backslash$ bibinfo $\{$ doi $\}\{10.1016 /$ j.desal.2010.07.039\}. URL http:// linkinghub.elsevier.com/retrieve/pii/S0011916410005370.

[34] Taherian, H., Rezania, A., Sadeghi, S., Ganji, D.. Experimental validation of dynamic simulation of the flat plate collector in a closed thermosyphon solar water heater. Energy Conversion and Management 2011;52(1):301-307. doi: \bibinfo\{doi $\{$ \{10.1016/j.enconman. 2010.06.063\}. URL http://linkinghub.elsevier.com/retrieve/ pii/S0196890410002840.

[35] Powell, C., Bender, T., Lawryshyn, Y.. A model to determine financial indicators for organic solar cells. Solar Energy 2009;83(11):19771984. doi:\bibinfo\{doi\}\{10.1016/j.solener.2009.07.009\}. URL http: //linkinghub.elsevier.com/retrieve/pii/S0038092X09001777.

[36] Agrawal, B., Tiwari, G.. Optimizing the energy and exergy of building integrated photovoltaic thermal (BIPVT) systems under cold climatic conditions. Applied Energy 2010;87(2):417-426. doi: bibinfo\{doi $\}\{10$. 1016/j.apenergy.2009.06.011\}. URL http://linkinghub.elsevier. com/retrieve/pii/S0306261909002505.

[37] Firth, S., Lomas, K., Wright, A.. Targeting household energyefficiency measures using sensitivity analysis. Building Research \& Information 2010;(1):25-41. URL http://www.informaworld.com/ smpp/content $\sim \mathrm{db}=\mathrm{all} \sim$ content $=\mathrm{a} 916939085$.

[38] Yun, G., Steemers, K.. Implications of urban settings for the design of photovoltaic and conventional façades. Solar Energy 2009;83(1):6980. doi: bibinfo\{doi\}\{10.1016/j.solener.2008.06.007\}. URL http:// linkinghub.elsevier.com/retrieve/pii/S0038092X0800159X. 
[39] Anagreh, Y., Bataineh, A., Al-Odat, M.. Assessment of renewable energy potential, at Aqaba in Jordan. Renewable and Sustainable Energy Reviews 2010;14(4):1347-1351. doi: \bibinfo\{doi\}\{10.1016/j.rser. 2009.12.007\}. URL http://linkinghub.elsevier.com/retrieve/ pii/S1364032109002871.

[40] Shimazaki, Y.. Evaluation of refrigerating and air-conditioning technologies in heat cascading systems under the carbon dioxide emissions constraint: the proposal of the energy cascade balance table. Energy Policy 2003;31(15):1685-1697. doi: bibinfo\{doi\}\{10.1016/ S0301-4215(02)00236-7\}. URL http://linkinghub.elsevier.com/ retrieve/pii/S0301421502002367.

[41] Farmahini Farahani, M., Heidarinejad, G., Delfani, S.. A twostage system of nocturnal radiative and indirect evaporative cooling for conditions in Tehran. Energy and Buildings 2010;42(11):21312138. doi: \bibinfo\{doi\}\{10.1016/j.enbuild.2010.07.003\}. URL http: //linkinghub.elsevier.com/retrieve/pii/S0378778810002197.

[42] Bagiorgas, H., Mihalakakou, G.. Experimental and theoretical investigation of a nocturnal radiator for space cooling. Renewable Energy 2008;33(6):1220-1227. doi: bibinfo\{doi\}\{10.1016/j.renene.2007. 04.015\}. URL http://linkinghub.elsevier.com/retrieve/pii/ S096014810700136X.

[43] Lukas, M., Lee, K., Ghezel-Ayagh, H.. Development of a stack simulation model for control study on direct reforming molten carbonate fuel cell power plant. IEEE Transactions on Energy Conversion 1999;14(4):1651-1657. doi: \bibinfo $\{$ doi $\}\{10.1109 / 60.815119\}$. 
URL http://ieeexplore.ieee.org/lpdocs/epic03/wrapper.htm? arnumber $=815119$.

[44] Sufian, M.a., Bala, B.K.. Modeling of urban solid waste management system: the case of Dhaka city. Waste management (New York, NY) 2007;27(7):858-68. doi:\bibinfo\{doi\}\{10.1016/j.wasman.2006.04.011\}. URL http://www .ncbi.nlm.nih.gov/pubmed/16781136.

[45] Sufian, M.A., Bala, B.K.. Modeling of urban solid waste management system: the case of Dhaka city. Waste management (New York, NY) 2007;27(7):858-68. doi: \bibinfo\{doi\}\{10.1016/j.wasman.2006.04.011\}. URL http://www .ncbi.nlm.nih.gov/pubmed/16781136.

[46] Zamorano, M., Pérez Pérez, J.I., Aguilar Pavés, I., Ramos Ridao, A.. Study of the energy potential of the biogas produced by an urban waste landfill in Southern Spain. Renewable and Sustainable Energy Reviews 2007;11(5):909-922. doi: \bibinfo\{doi\}\{10.1016/j.rser. 2005.05.007\}. URL http://linkinghub.elsevier.com/retrieve/ pii/S1364032105000602.

[47] Sekine, Y., Fukuda, K., Kato, K., Adachi, Y., Matsuno, Y.. $\mathrm{CO} 2$ reduction potentials by utilizing waste plastics in steel works. The International Journal of Life Cycle Assessment 2009;14(2):122136. doi: bibinfo $\{$ doi $\}\{10.1007 /$ s11367-008-0055-3\}. URL http:// WWW. springerlink.com/index/10.1007/s11367-008-0055-3.

[48] Wada, Y., Okumoto, T., Wada, N.. Evaluating waste disposal systems. Journal of Material Cycles and Waste Management 2008;10(2):173-187. doi: \bibinfo\{doi\}\{10.1007/ 
s10163-008-0209-1\}. URL http://www.springerlink.com/index/ $10.1007 / \mathrm{s} 10163-008-0209-1$.

[49] Chantrelle, F.P., Lahmidi, H., Keilholz, W., Mankibi, M.E., Michel, P.. Development of a multicriteria tool for optimizing the renovation of buildings. Applied Energy 2011;88(4):1386-1394. doi: \bibinfo\{doi\}\{10. 1016/j.apenergy.2010.10.002\}. URL http://linkinghub.elsevier. com/retrieve/pii/S0306261910003971.

[50] Kämpf, J.H., Robinson, D.. Optimisation of building form for solar energy utilisation using constrained evolutionary algorithms. Energy and Buildings 2010;42(6):807-814. doi: \bibinfo\{doi $\}\{10.1016 / j$.enbuild. 2009.11.019\}. URL http://linkinghub.elsevier.com/retrieve/ pii/S0378778809003156.

[51] Wei, Y., Guo-qiang, Z., Xiao, W., Jing, L., San-xian, X.. Potential model for single-sided naturally ventilated buildings in China. Solar Energy 2010;84(9):1595-1600. doi: bibinfo\{doi\}\{10.1016/j.solener. 2010.06.011\}. URL http://linkinghub.elsevier.com/retrieve/ pii/S0038092X10002227.

[52] Hamilton, I., Summerfield, A., Steadman, J.P., Stone, A., Davies, M.. Exploring energy integration between new and existing developments. Building Research \& Information 2010;38(6):593-609. doi: \bibinfo\{doi $\}\{10.1080 / 09613218.2010$. 499214\}. URL http://www.informaworld.com/openurl?genre= article\&doi=10.1080/09613218.2010.499214\&magic=crossref ID404A21C5BB053405B1A640AFFD44AE3.

[53] Ihara, T., Kikegawa, Y., Asahi, K., Genchi, Y., Kondo, H.. Changes 
in year-round air temperature and annual energy consumption in office building areas by urban heat-island countermeasures and energy-saving measures. Applied Energy 2008;85(1):12-25. doi: \bibinfo\{doi\}\{10. 1016/j.apenergy.2007.06.012\}. URL http://linkinghub.elsevier. com/retrieve/pii/S0306261907000888.

[54] Eskin, N., Türkmen, H.. Analysis of annual heating and cooling energy requirements for office buildings in different climates in Turkey. Energy and Buildings 2008;40(5):763-773. doi: \bibinfo\{doi\}\{10.1016/ j.enbuild.2007.05.008\}. URL http://linkinghub.elsevier.com/ retrieve/pii/S0378778807001685.

[55] Karagiorgas, M., Tsoutsos, T., Moiapol, A.. A simulation of the energy consumption monitoring in Mediterranean hotels: Application in Greece. Energy and Buildings 2007;39(4):416426. doi: \bibinfo\{doi $\{$ 10.1016/j.enbuild.2006.07.008\}. URL http: //linkinghub.elsevier.com/retrieve/pii/S0378778806002143.

[56] Koroneos, C., Kottas, G.. Energy consumption modeling analysis and environmental impact assessment of model house in Thessaloniki-Greece. Building and Environment 2007;42(1):122138. doi: \bibinfo\{doi\}\{10.1016/j.buildenv.2005.08.009\}. URL http: //linkinghub.elsevier.com/retrieve/pii/S0360132305003318.

[57] Akbari, H., Konopacki, S.. Calculating energy-saving potentials of heat-island reduction strategies. Energy Policy 2005;33(6):721756. doi: \bibinfo\{doi\}\{10.1016/j.enpol.2003.10.001\}. URL http:// linkinghub.elsevier.com/retrieve/pii/s0301421503003033.

[58] Defraeye, T., Carmeliet, J.. A methodology to assess the influ- 
ence of local wind conditions and building orientation on the convective heat transfer at building surfaces. Environmental Modelling \& Software 2010;25(12):1813-1824. doi: \bibinfo\{doi\}\{10.1016/j.envsoft. 2010.06.002\}. URL http://linkinghub.elsevier.com/retrieve/ pii/S1364815210001908.

[59] Mavrogianni, A., Davies, M., Chalabi, Z., Wilkinson, P., Kolokotroni, M., Milner, J.. Space heating demand and heatwave vulnerability: London domestic stock. Building Research \& Information 2009;37(5):583-597. doi: \bibinfo\{doi $\}\{10$. 1080/09613210903162597\}. URL http://www.informaworld.com/ openurl?genre=article\&doi=10.1080/09613210903162597\&magic= crossref | D404A21C5BB053405B1A640AFFD44AE3.

[60] Kolokotroni, M., Zhang, Y., Watkins, R.. The London Heat Island and building cooling design. Solar Energy 2007;81(1):102110. doi: \bibinfo $\{$ doi $\}\{10.1016 /$ j.solener.2006.06.005\}. URL http: //linkinghub.elsevier.com/retrieve/pii/S0038092X06001757.

[61] Hutchinson, E., Wilkinson, P., Hong, S., Oreszczyn, T.. Can we improve the identification of cold homes for targeted home energy-efficiency improvements? Applied Energy 2006;83(11):11981209. doi: bibinfo\{doi\}\{10.1016/j.apenergy.2006.01.007\}. URL http: //linkinghub.elsevier.com/retrieve/pii/S0306261906000109.

[62] Rylatt, M., Gadsden, S., Lomas, K.. Using GIS to estimate the replacement potential of solar energy for urban dwellings. Environment and Planning B: Planning and Design 2003;30(1):51-68. doi: \bibinfo $\{$ doi $\}\{10.1068 /$ b12931\}. URL http://www .envplan.com/ abstract.cgi?id=b12931. 
[63] Shimoda, Y., Okamura, T., Yamaguchi, Y., Yamaguchi, Y., Taniguchi, A., Morikawa, T.. City-level energy and CO2 reduction effect by introducing new residential water heaters. Energy 2010;35(12):4880-4891. doi: \bibinfo\{doi\} \{10.1016/j.energy.2010. 08.043\}. URL http://linkinghub.elsevier.com/retrieve/pii/ S0360544210004792.

[64] Meloni, I., Portoghese, A., Bez, M., Spissu, E.. Effects of Physical Activity on Propensity for Sustainable Trips. Transportation Research Record: Journal of the Transportation Research Board 2009;2134(-1):43-50. doi: \bibinfo $\{$ doi $\}\{10.3141 /$ 2134-06\}. URL http://trb.metapress.com/openurl.asp?genre= article\&id=doi:10.3141/2134-06.

[65] Jovic, J., Djoric, V.. Application of transport demand modeling in pollution estimation of a street network. Thermal Science 2009;13(3):229243. doi: \bibinfo\{doi $\{$ 10.2298/TSCI0903229J\}. URL http://www . doiserbia.nb.rs/Article.aspx?ID=0354-98360903229J.

[66] Nicolas, J.P.. Analysing road traffic influences on air pollution: How to achieve sustainable urban development. Transport Reviews 2000;20(2):219-232. doi: \bibinfo\{doi $\}\{10.1080 /$ 014416400295266\}. URL http://www.informaworld.com/openurl? genre=article\&doi=10.1080/014416400295266\&magic=crossref | | D404A21C5BB053405B1A640AFFD44AE3.

[67] Ye, H., Wang, K., Zhao, X., Chen, F., Li, X., Pan, L.. Relationship between construction characteristics and carbon emissions from urban household operational energy usage. Energy and Buildings 2011;43(1):147-152. doi: \bibinfo\{doi\}\{10.1016/j.enbuild. 
2010.09.002\}. URL http://linkinghub.elsevier.com/retrieve/ pii/S0378778810003129.

[68] Jo, J., Carlson, J., Golden, J., Bryan, H.. Sustainable urban energy: Development of a mesoscale assessment model for solar reflective roof technologies. Energy Policy 2010;38(12):7951-7959. doi: $\backslash$ bibinfo\{doi\} \{10.1016/j.enpol.2010.09.016\}. URL http://linkinghub.elsevier. com/retrieve/pii/S0301421510007020.

[69] Jo, J., Carlson, J., Golden, J., Bryan, H.. An integrated empirical and modeling methodology for analyzing solar reflective roof technologies on commercial buildings. Building and Environment 2010;45(2):453-460. doi: bibinfo\{doi\}\{10.1016/j.buildenv.2009. 07.001\}. URL http://linkinghub.elsevier.com/retrieve/pii/ S0360132309001693,

[70] Blengini, G.. Life cycle of buildings, demolition and recycling potential: A case study in Turin, Italy. Building and Environment 2009;44(2):319-330. doi: bibinfo\{doi\}\{10.1016/j.buildenv.2008. 03.007\}. URL http://linkinghub.elsevier.com/retrieve/pii/ S0360132308000450.

[71] Barnes, B., Cao, H., Drab, T., Pearson, J.. Design of Sustainable Relief Housing in Ethiopia: An Implementation of Cradle to Cradle Design in Earthbag Construction. American Journal of Environmental Sciences 2009;5(2):137-144. doi:〈bibinfo\{doi\}\{10.3844/ ajessp.2009.137.144\}. URL http://www.thescipub.com/abstract/ ?doi=ajessp.2009.137.144.

[72] Blocken, B., Defraeye, T., Derome, D., Carmeliet, J.. High- 
resolution CFD simulations for forced convective heat transfer coefficients at the facade of a low-rise building. Building and Environment 2009;44(12):2396-2412. doi: \bibinfo $\{$ doi $\}\{10.1016 / j . b u i l d e n v$. 2009.04.004\}. URL http://linkinghub.elsevier.com/retrieve/ pii/S0360132309001000.

[73] Wong, N.H., Tan, A.Y.K., Tan, P.Y., Wong, N.C.. Energy simulation of vertical greenery systems. Energy and Buildings 2009;41(12):14011408. doi: \bibinfo\{doi $\}\{10.1016 / j$.enbuild.2009.08.010\}. URL http: //linkinghub.elsevier.com/retrieve/pii/S037877880900190X.

[74] Bourgeois, D., Reinhart, C.F., Ward, G.. Standard daylight coefficient model for dynamic daylighting simulations. Building Research \& Information 2008;36(1):68-82. doi: \bibinfo\{doi $\}\{10$. 1080/09613210701446325\}. URL http://www.informaworld.com/ openurl?genre=article\&doi=10.1080/09613210701446325\&magic= crossref | |D404A21C5BB053405B1A640AFFD44AE3.

[75] Larsen, S., Filippín, C., Beascochea, A., Lesino, G.. An experience on integrating monitoring and simulation tools in the design of energy-saving buildings. Energy and Buildings 2008;40(6):987997. doi: \bibinfo\{doi $\}\{10.1016 /$ j.enbuild.2007.08.004\}. URL http: //linkinghub.elsevier.com/retrieve/pii/S0378778807002095.

[76] Kampf, J., Robinson, D.. A simplified thermal model to support analysis of urban resource flows. Energy and Buildings 2007;39(4):445453. doi: bibinfo\{doi\}\{10.1016/j.enbuild.2006.09.002\}. URL http:// linkinghub.elsevier.com/retrieve/pii/S0378778806002192.

[77] Aksoy, U., Inalli, M.. Impacts of some building passive design pa- 
rameters on heating demand for a cold region. Building and Environment 2006;41(12):1742-1754. doi: \bibinfo\{doi\}\{10.1016/j.buildenv. 2005.07.011\}. URL http://linkinghub.elsevier.com/retrieve/ pii/S0360132305002854

[78] Mathews, E., Richards, P.. An efficient tool for future building design. Building and Environment 1993;28(4):409-417. doi: \bibinfo\{doi $\}\{10$. 1016/0360-1323(93)90018-X\}. URL http://linkinghub.elsevier. com/retrieve/pii/036013239390018X.

[79] Assimakopoulos, M., Mihalakakou, G., Flocas, H.. Simulating the thermal behaviour of a building during summer period in the urban environment. Renewable Energy 2007;32(11):18051816. doi: \bibinfo $\{$ doi $\}\{10.1016 /$ j.renene.2006.08.003\}. URL http: //linkinghub.elsevier.com/retrieve/pii/S0960148106002515.

[80] Pillai, I., Banerjee, R.. Methodology for estimation of potential for solar water heating in a target area. Solar Energy 2007;81(2):162172. doi: bibinfo\{doi $\{$ 10.1016/j.solener.2006.04.009\}. URL http:// linkinghub.elsevier.com/retrieve/pii/S0038092X06001095.

[81] Yamaguchi, Y., Shimoda, Y., Mizuno, M.. Transition to a sustainable urban energy system from a long-term perspective: Case study in a Japanese business district. Energy and Buildings 2007;39(1):112. doi: \bibinfo $\{$ doi $\}\{10.1016 /$ j.enbuild.2006.03.031\}. URL http: //linkinghub.elsevier.com/retrieve/pii/S0378778806001368.

[82] Ali, M.T., Mokhtar, M., Chiesa, M., Armstrong, P.. A cooling change-point model of community-aggregate electrical load. Energy and Buildings 2011;43(1):28-37. doi: \bibinfo\{doi\}\{10.1016/j.enbuild. 
2010.07.025\}. URL http://linkinghub.elsevier.com/retrieve/ pii/S0378778810002550.

[83] Lee, Y.S., Tong, L.I.. Forecasting energy consumption using a grey model improved by incorporating genetic programming. Energy Conversion and Management 2011;52(1):147-152. doi: \bibinfo\{doi $\}\{10$. 1016/j.enconman.2010.06.053\}. URL http://linkinghub. elsevier. com/retrieve/pii/S0196890410002748.

[84] Karathodorou, N., Graham, D.J., Noland, R.B.. Estimating the effect of urban density on fuel demand. Energy Economics 2010;32(1):8692. doi: $\backslash$ bibinfo $\{$ doi $\}\{10.1016 /$ j.eneco.2009.05.005\}. URL http:// linkinghub.elsevier.com/retrieve/pii/S0140988309000772.

[85] Shahmohamadi, P., Ramly, A., Maulud, K.N.A.. Reducing urban heat island effects : A systematic review to achieve energy consumption balance. International Journal of Physical Sciences 2010;5(6):626-636.

[86] Akisawa, A.. Two model analyses of the urban structure of minimal transportation energy consumption. Applied Energy 1998;61(1):2539. doi: bibinfo\{doi\}\{10.1016/S0306-2619(98)00036-1\}. URL http: //linkinghub.elsevier.com/retrieve/pii/S0306261998000361.

[87] Rickaby, P.A.. Energy and urban development in an archetypal English town. Environment and Planning B: Planning and Design 1991;18(2):153-175. doi: bibinfo\{doi\}\{10.1068/b180153\}. URL http: //www.envplan.com/abstract.cgi?id=b180153.

[88] Kalma, J.. Energy use and the atmospheric environment in Hong Kong: Part II. Waste heat, land use and urban climate. Urban Ecology 1978;3(1):59-83. doi:〈bibinfo\{doi\}\{10.1016/0304-4009(78) 
90030-X\}. URL http://linkinghub.elsevier.com/retrieve/pii/ 030440097890030X.

[89] Karkheck, J., Powell, J., Beardsworth, E.. Prospects for district heating in the United States. Science (New York, NY) 1977;195(4282):94855. doi: \bibinfo\{doi $\}\{10.1126 /$ science.195.4282.948\}. URL http:// WwW.ncbi.nlm.nih.gov/pubmed/17735654.

[90] Hong, S.H., Gilbertson, J., Oreszczyn, T., Green, G., Ridley, I.. A field study of thermal comfort in low-income dwellings in England before and after energy efficient refurbishment. Building and Environment 2009;44(6):1228-1236. doi: \bibinfo $\{$ doi $\}\{10.1016 / j . b u i l d e n v$. 2008.09.003\}. URL http://linkinghub.elsevier.com/retrieve/ pii/S0360132308002254.

[91] Tanimoto, J., Hagishima, A., Sagara, H.. A methodology for peak energy requirement considering actual variation of occupants' behavior schedules. Building and Environment 2008;43(4):610619. doi: \bibinfo\{doi $\}\{10.1016 / j$.buildenv.2006.06.034\}. URL http: //linkinghub.elsevier.com/retrieve/pii/S0360132306003325.

[92] Liu, J., Wang, R., Yang, J.. Metabolism and Driving Forces of Chinese Urban Household Consumption. Population and Environment 2005;26(4):325-341. doi: \bibinfo\{doi\}\{10.1007/ s11111-005-3345-8\}. URL http://www.springerlink.com/index/ $10.1007 / \mathrm{s} 11111-005-3345-8$.

[93] Ratti, C., Baker, N., Steemers, K.. Energy consumption and urban texture. Energy and Buildings 2005;37(7):762- 
776. doi: bibinfo\{doi $\}\{10.1016 /$ j.enbuild.2004.10.010\}. URL http: //linkinghub.elsevier.com/retrieve/pii/S0378778804003391.

[94] Gorgolewski, M.. Optimising renovation strategies for energy conservation in housing. Building and Environment 1995;30(4):583589. doi: \bibinfo $\{$ doi $\}\{10.1016 / 0360-1323(95) 00011-T\}$. URL http: //linkinghub.elsevier.com/retrieve/pii/036013239500011T.

[95] Anderson, B., Chapman, P.F., Cutland, N.G., Dickson, C.M., Doran, S., Henderson, G., et al. BREDEM-8 Model description. 2001 update. Tech. Rep.; Building Research Establishment, Report BR 439; 2002.

[96] Michalik, G., Khan, M.E., Bonwick, W.J., Mielczarksi, W.. Structural modelling of energy demand in the residential sector: 1. Development of structural models. Energy 1997;22(10):937-947. doi: \bibinfo\{doi\}\{10.1016/S0360-5442(97)00029-7\}. URL http:// linkinghub.elsevier.com/retrieve/pii/S0360544297000297.

[97] Michalik, G., Khan, M.E., Bonwick, W.J., Mielczarksi, W.. structural modelling of energy demand in the residential sector: 2. THE USE OF LINGUISTIC VARIABLES TO INCLUDE UNCERTAINTY OF CUSTOMERS' Behaviour. Science 1997;22(10):949-958.

[98] Shimoda, Y.. Residential end-use energy simulation at city scale. Building and Environment 2004;39(8):959-967. doi: \bibinfo\{doi\}\{10. 1016/j.buildenv.2004.01.020\}. URL http://linkinghub.elsevier. com/retrieve/pii/S0360132304000319.

[99] Shimoda, Y., Asahi, T., Taniguchi, a., Mizuno, M.. Evaluation of city-scale impact of residential energy conservation measures using the detailed end-use simulation model. Energy 2007;32(9):1617- 
1633. doi: \bibinfo\{doi $\}\{10.1016 /$ j.energy.2007.01.007\}. URL http: //linkinghub.elsevier.com/retrieve/pii/S0360544207000217.

[100] Bennett, M.. Auditing energy use in cities. Energy Policy 2001;29(2):125-134. doi:〈bibinfo\{doi\}\{10.1016/S0301-4215(00) 00108-7\}. URL http://linkinghub.elsevier.com/retrieve/pii/ S0301421500001087.

[101] Mendes, M., Aramaki, T., Hanaki, K.. Comparison of the environmental impact of incineration and landfilling in São Paulo City as determined by LCA. Resources, Conservation and Recycling 2004;41(1):4763. doi: bibinfo\{doi\}\{10.1016/j.resconrec.2003.08.003\}. URL http: //linkinghub.elsevier.com/retrieve/pii/S0921344903001204.

[102] Jones, P., Patterson, J., Lannon, S.. Modelling the built environment at an urban scale - Energy and health impacts in relation to housing. Landscape and Urban Planning 2007;83(1):39-49. doi: bibinfo\{doi\}\{10.1016/j.landurbplan.2007.05.015\}. URL http:// linkinghub.elsevier.com/retrieve/pii/S0169204607001430.

[103] Robinson, D., Campbell, N., Gaiser, W., Kabel, K., Lemouel, a., Morel, N., et al. SUNtool - A new modelling paradigm for simulating and optimising urban sustainability. Solar Energy 2007;81(9):11961211. doi: bibinfo\{doi\}\{10.1016/j.solener.2007.06.002\}. URL http: //linkinghub.elsevier.com/retrieve/pii/S0038092X0700120X.

[104] Yamaguchi, Y., Shimoda, Y., Mizuno, M.. Proposal of a modeling approach considering urban form for evaluation of city level energy management. Energy and Buildings 2007;39(5):580- 
592. doi: bibinfo\{doi $\}\{10.1016 /$ j.enbuild.2006.09.011\}. URL http: //linkinghub.elsevier.com/retrieve/pii/S0378778806002337.

[105] Girardin, L., Marechal, F., Dubuis, M., Calame-Darbellay, N., Favrat, D.. EnerGis: A geographical information based system for the evaluation of integrated energy conversion systems in urban areas. Energy 2010;35(2):830-840. doi: \bibinfo\{doi $\}\{10.1016 / j$.energy. 2009.08.018\}. URL http://linkinghub.elsevier.com/retrieve/ pii/S0360544209003582.

[106] Parshall, L., Gurney, K., Hammer, S.a., Mendoza, D., Zhou, Y., Geethakumar, S.. Modeling energy consumption and CO2 emissions at the urban scale: Methodological challenges and insights from the United States. Energy Policy 2010;38(9):4765-4782. doi: \bibinfo\{doi\} $\{10.1016 /$ j.enpol.2009.07.006\}. URL http://linkinghub.elsevier. com/retrieve/pii/S0301421509005163.

[107] Dong, B., Kennedy, C., Pressnail, K.. Comparing life cycle implications of building retrofit and replacement options. Canadian Journal of Civil Engineering 2005;1063:1051-1063. doi: \bibinfo\{doi\}\{10.1139/ L05-061\}.

[108] Bizzarri, G., Morini, G.. New technologies for an effective energy retrofit of hospitals. Applied Thermal Engineering 2006;26(2-3):161-169. doi: \bibinfo\{doi\}\{10.1016/j.applthermaleng. 2005.05.015\}. URL http://linkinghub.elsevier.com/retrieve/ pii/S1359431105001821.

[109] Chen, H., Ooka, R., Iwamura, K., Huang, H., Yoshizawa, N., Miisho, K., et al. Study on sustainable redevelopment of 
a densely built-up area in Tokyo by introducing a distributed local energy supply system. Energy and Buildings 2008;40(5):782792. doi: \bibinfo\{doi\}\{10.1016/j.enbuild.2007.05.012\}. URL http: //linkinghub.elsevier.com/retrieve/pii/S0378778807001703.

[110] Thyholt, M., Hestnes, a.. Heat supply to low-energy buildings in district heating areasAnalyses of $\mathrm{CO} 2$ emissions and electricity supply security. Energy and Buildings 2008;40(2):131139. doi: \bibinfo\{doi $\}\{10.1016 /$ j.enbuild.2007.01.016 . URL http: //linkinghub.elsevier.com/retrieve/pii/S0378778807000369.

[111] Genon, G., Torchio, M., Poggio, a., Poggio, M.. Energy and environmental assessment of small district heating systems: Global and local effects in two case-studies. Energy Conversion and Management 2009;50(3):522-529. doi: \bibinfo\{doi $\}\{10.1016 /$ j.enconman. 2008.11.010\}. URL http://linkinghub.elsevier.com/retrieve/ pii/S0196890408004573.

[112] Kamimura, A., Guerra, S., Sauer, I.. On the substitution of energy sources: Prospective of the natural gas market share in the Brazilian urban transportation and dwelling sectors. Energy Policy 2006;34(18):3583-3590. doi: \bibinfo $\{$ doi $\}\{10.1016 /$ j.enpol.2005. 07.020\}. URL http://linkinghub.elsevier.com/retrieve/pii/ S0301421505002041.

[113] Mavrogianni, A., Davies, M., Batty, M., Belcher, S., Bohnenstengel, S., Carruthers, D., et al. The comfort, energy and health implications of London's urban heat island. Building Services Engineering Research and Technology 2011;32(1):35-52. doi: \bibinfo\{doi\} 
\{10.1177/0143624410394530\}. URL http://bse.sagepub.com/cgi/ doi/10.1177/0143624410394530.

[114] Kolokotroni, M., Davies, M., Croxford, B., Bhuiyan, S., Mavrogianni, A.. A validated methodology for the prediction of heating and cooling energy demand for buildings within the Urban Heat Island: Case-study of London. Solar Energy 2010;84(12):22462255. doi:〈bibinfo\{doi $\{10.1016 / j$.solener.2010.08.002\}. URL http: //linkinghub.elsevier.com/retrieve/pii/S0038092X10002616.

[115] Kikegawa, Y.. Development of a numerical simulation system toward comprehensive assessments of urban warming countermeasures including their impacts upon the urban buildings' energydemands. Applied Energy 2003;76(4):449-466. doi: \bibinfo\{doi $\}\{10$. 1016/S0306-2619(03)00009-6\}. URL http://linkinghub.elsevier. com/retrieve/pii/S0306261903000096.

[116] Beccali, M., Cellura, M., Lobrano, V., Marvuglia, A.. Short-term prediction of household electricity consumption: Assessing weather sensitivity in a Mediterranean area. Renewable and Sustainable Energy Reviews 2008;12(8):2040-2065. doi: \bibinfo\{doi\}\{10.1016/j.rser. 2007.04.010\}. URL http://linkinghub.elsevier.com/retrieve/ pii/S1364032107000664.

[117] Wang, Y., Tian, W., Zhu, L., Ren, J., Liu, Y., Zhang, J., et al. Interactions between Building Integrated Photovoltaics and Microclimate in Urban Environments. Journal of Solar Energy Engineering 2006;128(2):168. doi: bibinfo\{doi\}\{10.1115/1.2188533\}. URL http://link.aip.org/link/JSEEDO/v128/i2/p168/s1\&Agg=doi. 
[118] Meyn, S.K., Oke, T.. Heat fluxes through roofs and their relevance to estimates of urban heat storage. Energy and Buildings 2009;41(7):745752. doi: \bibinfo\{doi\}\{10.1016/j.enbuild.2009.02.005\}. URL http:// linkinghub.elsevier.com/retrieve/pii/S0378778809000401.

[119] Oxizidis, S., Dudek, A., Papadopoulos, A.. A computational method to assess the impact of urban climate on buildings using modeled climatic data. Energy and Buildings 2008;40(3):215223. doi: \bibinfo\{doi $\}\{10.1016 /$ j.enbuild.2007.02.018\}. URL http: //linkinghub.elsevier.com/retrieve/pii/S0378778807000722.

[120] Chwieduk, D.. Some aspects of modelling the energy balance of a room in regard to the impact of solar energy. Solar Energy 2008;82(10):870884. doi: \bibinfo\{doi\}\{10.1016/j.solener.2008.04.004\}. URL http:// linkinghub.elsevier.com/retrieve/pii/S0038092X08000832.

[121] Williamson, T., Erell, E.. The Implications for Building Ventilation of the Spatial and Temporal Variability of Air Temperature in the Urban Canopy Layer. INTERNATIONAL JOURNAL OF VENTILATION 2008;7(1):23-36.

[122] Zhu, Y., Liu, J., Hagishima, A., Tanimoto, J., Yao, Y., Ma, Z.. Evaluation of coupled outdoor and indoor thermal comfort environment and anthropogenic heat. Building and Environment 2007;42(2):10181025. doi: \bibinfo\{doi\}\{10.1016/j.buildenv.2005.10.019\}. URL http: //linkinghub.elsevier.com/retrieve/pii/S0360132305004580.

[123] Gui, J.G., Carlson, J., Phelan, P.E., Kaloush, K.E., Golden, J.S.. Impact of Pavement Thickness on Surface Diurnal Temperatures. Journal of Green Building 2007;2(2):121-130. doi: \bibinfo\{doi $\}\{10$. 
3992/jgb.2.2.121\}. URL http://www.atypon-link.com/CPUB/doi/ $\mathrm{abs} / 10.3992 / \mathrm{jgb} .2 .2 .121$.

[124] Robinson, D., Stone, A.. Internal illumination prediction based on a simplified radiosity algorithm. Solar Energy 2006;80(3):260267. doi: \bibinfo $\{$ doi $\}\{10.1016 /$ j.solener.2005.02.016 . URL http: //linkinghub.elsevier.com/retrieve/pii/S0038092X05000952.

[125] Wang, Z.H., Bou-Zeid, E., Smith, J.A.. A Spatially-Analytical Scheme for Surface Temperatures and Conductive Heat Fluxes in Urban Canopy Models. Boundary-Layer Meteorology 2010;138(2):171193. doi: bibinfo $\{$ doi $\}\{10.1007 /$ s10546-010-9552-6 $\}$. URL http:// WWW.springerlink.com/index/10.1007/s10546-010-9552-6.

[126] Yezioro, A., Capeluto, I., Shaviv, E.. Design guidelines for appropriate insolation of urban squares. Renewable Energy 2006;31(7):10111023. doi: \bibinfo\{doi $\}\{10.1016 /$ j.renene.2005.05.015\}. URL http: //linkinghub.elsevier.com/retrieve/pii/S0960148105001503.

[127] Chow, W.T.L., Pope, R.L., Martin, C.A., Brazel, A.J.. Observing and modeling the nocturnal park cool island of an arid city: horizontal and vertical impacts. Theoretical and Applied Climatology 2010;103(1-2):197-211. doi: \bibinfo\{doi\}\{10.1007/ s00704-010-0293-8\}. URL http://www.springerlink.com/index/ 10.1007/s00704-010-0293-8.

[128] Ooka, R., Sato, T., Harayama, K., Murakami, S., Kawamoto, Y.. Thermal Energy Balance Analysis of the Tokyo Metropolitan Area Using a Mesoscale Meteorological Model Incorporating an Urban Canopy Model. Boundary-Layer Meteorology 2010;138(1):77- 
97. doi: \bibinfo $\{$ doi $\}\{10.1007 /$ s10546-010-9550-8\}. URL http://www . springerlink.com/index/10.1007/s10546-010-9550-8.

[129] Bourbia, F., Boucheriba, F.. Impact of street design on urban microclimate for semi arid climate (Constantine). Renewable Energy 2010;35(2):343-347. doi: \bibinfo\{doi\}\{10.1016/j.renene.2009. 07.017\}. URL http://linkinghub.elsevier.com/retrieve/pii/ S0960148109003140.

[130] Lin, T.P.. Thermal perception, adaptation and attendance in a public square in hot and humid regions. Building and Environment 2009;44(10):2017-2026. doi: \bibinfo $\{$ doi $\}\{10.1016 / j . b u i l d e n v$. 2009.02.004\}. URL http://linkinghub.elsevier.com/retrieve/ pii/S0360132309000432.

[131] Coutts, A.M., Beringer, J., Tapper, N.J.. Investigating the climatic impact of urban planning strategies through the use of regional climate modelling: a case study for Melbourne, Australia. International Journal of Climatology 2008;28(14):1943-1957. doi: \bibinfo\{doi\}\{10.1002/ joc.1680\}. URL http://doi.wiley.com/10.1002/joc.1680.

[132] Gulyas, A., Unger, J., Matzarakis, A.. Assessment of the microclimatic and human comfort conditions in a complex urban environment: Modelling and measurements. Building and Environment 2006;41(12):1713-1722. doi: \bibinfo $\{$ doi $\}\{10.1016 /$ j.buildenv. 2005.07.001\}. URL http://linkinghub.elsevier.com/retrieve/ pii/S036013230500274X.

[133] Mirzaei, P.A., Haghighat, F.. Approaches to study Urban Heat Island - Abilities and limitations. Building and Environ- 
ment 2010;45(10):2192-2201. doi: \bibinfo $\{$ doi $\}\{10.1016 / j$.buildenv. 2010.04.001\}. URL http://linkinghub.elsevier.com/retrieve/ pii/S0360132310001083

[134] Idczak, M., Groleau, D., Mestayer, P., Rosant, J.M., Sini, J.F.. An application of the thermo-radiative model SOLENE for the evaluation of street canyon energy balance. Building and Environment 2010;45(5):1262-1275. doi: \bibinfo\{doi $\}\{10.1016 / j$.buildenv. 2009.11.011\}. URL http://linkinghub.elsevier.com/retrieve/ pii/S0360132309003369.

[135] Marciotto, E.R., Oliveira, A.P., Hanna, S.R.. Modeling study of the aspect ratio influence on urban canopy energy fluxes with a modified wall-canyon energy budget scheme. Building and Environment 2010;45(11):2497-2505. doi: \bibinfo\{doi\}\{10.1016/j.buildenv. 2010.05.012\}. URL http://linkinghub.elsevier.com/retrieve/ pii/S0360132310001502.

[136] Alexandri, E., Jones, P.. Temperature decreases in an urban canyon due to green walls and green roofs in diverse climates. Building and Environment 2008;43(4):480-493. doi: \bibinfo\{doi\}\{10.1016/j.buildenv. 2006.10.055\}. URL http://linkinghub.elsevier.com/retrieve/ pii/S0360132306003957.

[137] Tian, W., Wang, Y., Xie, Y., Wu, D., Zhu, L., Ren, J.. Effect of building integrated photovoltaics on microclimate of urban canopy layer. Building and Environment 2007;42(5):18911901. doi: \bibinfo\{doi\}\{10.1016/j.buildenv.2006.02.022\}. URL http: //linkinghub.elsevier.com/retrieve/pii/S0360132306000680. 
[138] Alitoudert, F., Mayer, H.. Numerical study on the effects of aspect ratio and orientation of an urban street canyon on outdoor thermal comfort in hot and dry climate. Building and Environment 2006;41(2):94108. doi: \bibinfo\{doi\}\{10.1016/j.buildenv.2005.01.013\}. URL http: //linkinghub.elsevier.com/retrieve/pii/S0360132305000120.

[139] Bozonnet, E., Belarbi, R., Allard, F.. Modelling solar effects on the heat and mass transfer in a street canyon, a simplified approach. Solar Energy 2005;79(1):10-24. doi: \bibinfo\{doi\}\{10.1016/j.solener. 2004.10.007\}. URL http://linkinghub.elsevier.com/retrieve/ pii/S0038092X04003196.

[140] Hamilton, I., Davies, M., Steadman, P., Stone, A., Ridley, I., Evans, S.. The significance of the anthropogenic heat emissions of London's buildings: A comparison against captured shortwave solar radiation. Building and Environment 2009;44(4):807-817. doi: \bibinfo\{doi\}\{10. 1016/j.buildenv.2008.05.024\}. URL http://linkinghub.elsevier. com/retrieve/pii/S0360132308001418.

[141] Dhakal, S., Hanaki, K.. Improvement of urban thermal environment by managing heat discharge sources and surface modification in Tokyo. Energy and Buildings 2002;34(1):13-23. doi: \bibinfo\{doi\}\{10.1016/ S0378-7788(01)00084-6\}. URL http://linkinghub.elsevier.com/ retrieve/pii/S0378778801000846.

[142] Kikegawa, Y., Genchi, Y., Kondo, H., Hanaki, K.. Impacts of city-block-scale countermeasures against urban heat-island phenomena upon a building's energy-consumption for air-conditioning. Applied Energy 2006;83(6):649-668. doi: \bibinfo\{doi\}\{10.1016/j.apenergy.2005. 
06.001\}. URL http://linkinghub.elsevier.com/retrieve/pii/ S0306261905000711.

[143] IEA, . World Energy Outlook. International Energy Agency; 2000.

[144] Manfren, M., Caputo, P., Costa, G.. Paradigm shift in urban energy systems through distributed generation: Methods and models. Applied Energy 2011;88(4):1032-1048. doi: bibinfo\{doi\}\{10.1016/j.apenergy. 2010.10.018\}. URL http://linkinghub.elsevier.com/retrieve/ pii/S0306261910004204.

[145] Conti, S.. Integration of multiple PV units in urban power distribution systems. Solar Energy 2003;75(2):87-94. doi:\bibinfo\{doi\}\{10.1016/ S0038-092X(03)00249-4\}. URL http://linkinghub.elsevier.com/ retrieve/pii/S0038092X03002494.

[146] Tapia, F., Marianov, V., Vargas, L.. Optimal Capacity Expansion in Electric Power Subtransmission Networks. Journal of Energy Engineering 2009;135(3):98. doi: \bibinfo\{doi\}\{10.1061/ (ASCE)0733-9402(2009)135:3(98)\}. URL http://link.aip.org/ link/JLEED9/v135/i3/p98/s1\&Agg=doi

[147] Sauma, E.E.. Intertemporal Planning of Transmission Expansions in Restructured Electricity Markets. Journal of Energy Engineering 2009;135(3):73. doi: \bibinfo\{doi\}\{10.1061/(ASCE)0733-9402(2009) 135:3(73)\}. URL http://link . aip.org/link/JLEED9/v135/i3/p73/ s1\&Agg=doi.

[148] Huang, Y., Fan, Y., Johnson, N.. Multistage System Planning for Hydrogen Production and Distribution. Networks and Spatial Economics 2009;10(4):455-472. doi: \bibinfo\{doi\}\{10.1007/ 
s11067-009-9119-6\}. URL http://www.springerlink.com/index/ $10.1007 / \mathrm{s} 11067-009-9119-6$.

[149] Geng, Y., Tsuyoshi, F., Chen, X.. Evaluation of innovative municipal solid waste management through urban symbiosis: a case study of Kawasaki. Journal of Cleaner Production 2010;18(10-11):9931000. doi: bibinfo\{doi $\}\{10.1016 / j . j c l e p r o .2010 .03 .003\}$. URL http: //linkinghub.elsevier.com/retrieve/pii/S0959652610001034.

[150] Shrestha, R., Anandarajah, G., Adhikari, S., Jiang, K., Songli, Z.. Energy and environmental implications of NO emission reduction from the transport sector of Beijing: a least-cost planning analysis. Transportation Research Part D: Transport and Environment 2005;10(1):111. doi: \bibinfo\{doi $\}\{10.1016 / j . t r d .2004 .08 .007\}$. URL http:// linkinghub.elsevier.com/retrieve/pii/S1361920904000501.

[151] Greenberg, M., Mantell, N., Lahr, M., Felder, F., Zimmerman, R.. Short and intermediate economic impacts of a terroristinitiated loss of electric power: Case study of New Jersey. Energy Policy 2007;35(1):722-733. doi:\bibinfo\{doi\}\{10.1016/j.enpol. 2006.01.017\}. URL http://linkinghub.elsevier.com/retrieve/ pii/S0301421506000668.

[152] Mancarella, P., Gan, C., Strbac, G.. Optimal design of lowvoltage distribution networks for $\mathrm{CO} 2$ emission minimisation. Part II: Discrete optimisation of radial networks and comparison with alternative design strategies. IET Generation, Transmission \& Distribution 2011;5(1):47. doi: \bibinfo $\{$ doi $\}\{10.1049 /$ iet-gtd.2009.0291 $\}$. URL http://link.aip.org/link/IGTDAW/v5/i1/p47/s1\&Agg=doi. 
[153] Mancarella, P., Chicco, G.. Global and local emission impact assessment of distributed cogeneration systems with partial-load models. Applied Energy 2009;86(10):2096-2106. doi: \bibinfo\{doi $\}\{10$. 1016/j.apenergy.2008.12.026\}. URL http://linkinghub.elsevier. com/retrieve/pii/S0306261908003516.

[154] Zhang, L., Huang, Z.. Life cycle study of coal-based dimethyl ether as vehicle fuel for urban bus in China. Energy 2007;32(10):18961904. doi: bibinfo\{doi $\}\{10.1016 /$ j.energy.2007.01.009\}. URL http: //linkinghub.elsevier.com/retrieve/pii/S0360544207000291.

[155] Yoshino, D., Fujiwara, A., Zhang, J.. Environmental Efficiency Model Based on Data Envelopment Analysis and Its Application to Environmentally Sustainable Transport Policies. Transportation Research Record: Journal of the Transportation Research Board 2010;2163(-1):112-123. doi: \bibinfo\{doi\}\{10.3141/ 2163-13\}. URL http://trb.metapress.com/openurl.asp?genre= article\&id=doi:10.3141/2163-13.

[156] Horridge, M.. A computable general equilibrium model of urban transport demands. Journal of Policy Modeling 1994;16(4):427457. doi: \bibinfo $\{$ doi $\}\{10.1016 / 0161-8938(94) 90037-X\}$. URL http: //linkinghub.elsevier.com/retrieve/pii/016189389490037X.

[157] Berg, C.. Household Transport Demand in a CGE-framework. Environmental and Resource Economics 2006;37(3):573-597. doi: bibinfo $\{$ doi $\}\{10.1007 /$ s10640-006-9050-y.$\quad$ URL http: //www.springerlink.com/index/10.1007/s10640-006-9050-y.

[158] Ren, H., Zhou, W., Nakagami, K., Gao, W.. Integrated design and 
evaluation of biomass energy system taking into consideration demand side characteristics. Energy 2010;35(5):2210-2222. doi: \bibinfo\{doi\} \{10.1016/j.energy.2010.02.007\}. URL http://linkinghub.elsevier. com/retrieve/pii/S0360544210000599

[159] Lin, Q.G., Huang, G.H., Bass, B., Chen, B., Zhang, B.Y., Zhang, X.D.. CCEM: A City-cluster Energy Systems Planning Model. Energy Sources, Part A: Recovery, Utilization, and Environmental Effects 2009;31(4):273-286. doi: \bibinfo\{doi $\}\{10$. 1080/15567030802592345\}. URL http://www.informaworld.com/ openurl?genre=article\&do $i=10.1080 / 15567030802592345 \& \mathrm{mag} i \mathrm{c}=$ crossref | |D404A21C5BB053405B1A640AFFD44AE3.

[160] Farzaneh, H., Saboohi, Y.. Evaluation of the optimal performance of passenger vehicle by integrated energy-environment-economic modeling. International Journal of Environmental Science and Technology 2007;4(2):189-196.

[161] Ren, H., Gao, W.. A MILP model for integrated plan and evaluation of distributed energy systems. Applied Energy 2010;87(3):10011014. doi: \bibinfo $\{$ doi $\}\{10.1016 /$ j.apenergy.2009.09.023\}. URL http: //linkinghub.elsevier.com/retrieve/pii/S0306261909004152.

[162] Lozano, M.A., Ramos, J.C., Carvalho, M., Serra, L.M.. Structure optimization of energy supply systems in tertiary sector buildings. Energy and Buildings 2009;41(10):1063-1075. doi: \bibinfo\{doi $\}\{10$. 1016/j.enbuild.2009.05.008\}. URL http://linkinghub.elsevier. com/retrieve/pii/S037877880900111X.

[163] Gustafsson, S., Ronnqvist, M.. Optimal heating of large block of flats. 
Energy and Buildings 2008;40(9):1699-1708. doi: \bibinfo\{doi $\}\{10$. 1016/j.enbuild.2008.02.027\}. URL http://linkinghub.elsevier. com/retrieve/pii/S0378778808000595.

[164] Sugihara, H., Tomioka, H., Tsuji, K.. A competitive evaluation of urban energy systems from viewpoints of energy conservation and mitigating environmental impact. Electrical Engineering in Japan 2008;164(2):71-79. doi:〈bibinfo\{doi\}\{10.1002/eej.20421\}. URL http://doi.wiley.com/10.1002/eej.20421.

[165] Aki, H., Oyama, T., Tsuji, K.. Analysis of energy service systems in urban areas and their $\mathrm{CO} 2$ mitigations and economic impacts. Applied Energy 2006;83(10):1076-1088. doi: \bibinfo\{doi $\}\{10$. 1016/j.apenergy.2005.11.003\}. URL http://linkinghub.elsevier. com/retrieve/pii/S030626190500142X.

[166] Sugihara, H., Komoto, J., Tsuji, K.. A multi-objective optimization model for determining urban energy systems under integrated energy service in a specific area. Electrical Engineering in Japan 2004;147(3):20-31. doi:〈bibinfo\{doi\}\{10.1002/eej.10275\}. URL http://doi.wiley.com/10.1002/eej.10275.

[167] Aringhieri, R., Malucelli, F.. Optimal Operations Management and Network Planning of a District Heating System with a Combined Heat and Power Plant. 2003. URL http://www.springerlink.com/ content/m5q23h03r521r173/.

[168] Gustafsson, S., Karlsson, B., Sjöholm, B.. Differential rates for district heating and the influence on the optimal retrofit strategy for multi-family buildings. Heat Recovery Systems and 
CHP 1987;7(4):337-341. URL http://linkinghub.elsevier.com/ retrieve/pii/0890433287900950.

[169] Gustafsson, S., Karlsson, B.. Life-cycle cost minimization considering retrofits in multi-family residences. Energy and Buildings 1989;14:9 - 17. URL http://linkinghub.elsevier.com/retrieve/ pii/0378778889900248.

[170] Gustafsson, S., Karlsson, B.. Insulation and bivalent heating system optimization: Residential housing retrofits and time-of-use tariffs for electricity. Applied Energy 1989;34(4):303-315. doi: \bibinfo\{doi\}\{10. 1016/0306-2619(89)90035-4\}. URL http://linkinghub.elsevier. com/retrieve/pii/0306261989900354.

[171] Gustafsson, S.i., Systems, E.. STIG-INGE GUSTAFSSON, ANDERS LEWALD a n d BJ6RN G. KARLSSON Institute of Technology, Department of Mechanical Engineering, Energy Systems, S 58183 Link6ping, Sweden. Energy 1989;9(2):127-131.

[172] Gustafsson, S.. Optimization of building retrofits in a combined heat and power network. Energy 1992;17(2):161-171. doi: \bibinfo\{doi $\}\{10$. 1016/0360-5442(92)90065-8\}. URL http://linkinghub.elsevier. com/retrieve/pii/0360544292900658.

[173] Gustafsson, S.. Mixed integer linear programming and building retrofits. Energy and Buildings 1998;28(2):191-196. doi: $\backslash$ bibinfo $\{$ doi $\}\{10.1016 /$ S0378-7788(98)00019-X\}. URL http:// linkinghub.elsevier.com/retrieve/pii/S037877889800019X.

[174] Gustafsson, S.. Optimisation of insulation measures on existing buildings. Energy and Buildings 2000;33(1):49-55. doi: \bibinfo $\{$ doi $\}\{10$. 
1016/S0378-7788(00)00062-1\}. URL http://linkinghub.elsevier. com/retrieve/pii/S0378778800000621.

[175] Gustafsson, S.. Optimal fenestration retrofits by use of MILP programming technique. Energy and Buildings 2001;33(8):843-851. doi: bibinfo\{doi\}\{10.1016/S0378-7788(01)00065-2\}. URL http:// linkinghub.elsevier.com/retrieve/pii/s0378778801000652.

[176] Henning, D.. Cost minimization for a local utility through CHP, heat storage and load management. International Journal of Energy Research 1998;22(8):691-713. doi: \bibinfo\{doi\}\{10.1002/ (SICI)1099-114X(19980625)22:8<691::AID-ER395〉3.3.CO;2-5\} . URL http://doi.wiley.com/10.1002/(SICI)1099-114X(19980625)22: 8<691: :AID-ER395>3.3.C0;2-5.

[177] Sundberg, G., Karlsson, B.. Interaction effects in optimising a municipal energy system. Energy 2000;25(9):877-891. doi: \bibinfo\{doi $\}\{10$. 1016/S0360-5442(00)00022-0\}. URL http://linkinghub.elsevier. com/retrieve/pii/S0360544200000220.

[178] Asano, H., Sagai, S., Imamura, E., Ito, K., Yokoyama, R.. Impacts of time-of-use rates on the optimal sizing and operation of cogeneration systems. IEEE Transactions on Power Systems 1992;7(4):1444-1450. doi: \bibinfo\{doi\}\{10.1109/59.207366\}. URL http://ieeexplore. ieee.org/lpdocs/epic03/wrapper .htm?arnumber=207366.

[179] Bojic, M., Trifunovic, N., Gustafsson, S.. Mixed 0-1 sequential linear programming optimization of heat distribution in a district-heating system. Energy and Buildings 2000;32(3):309-317. doi: \bibinfo\{doi $\}\{10$. 
1016/S0378-7788(00)00058-X\}. URL http://linkinghub.elsevier. com/retrieve/pii/S037877880000058X.

[180] Dotzauer, E.. Experiences in mid-term planning of district heating systems. Energy 2003;28(15):1545-1555. doi: \bibinfo\{doi\}\{10.1016/ S0360-5442(03)00151-8\}. URL http://linkinghub.elsevier.com/ retrieve/pii/S0360544203001518.

[181] Chinese, D., Meneghetti, A.. Optimisation models for decision support in the development of biomass-based industrial districtheating networks in Italy. Applied Energy 2005;82(3):228-254. doi: \bibinfo\{doi\}\{10.1016/j.apenergy.2004.10.010\}. URL http:// linkinghub.elsevier.com/retrieve/pii/s0306261904001746.

[182] Pelet, X., Favrat, D., Leyland, G.. Multiobjective optimisation of integrated energy systems for remote communities considering economics and CO emissions. International Journal of Thermal Sciences 2005;44(12):1180-1189. doi: \bibinfo\{doi\}\{10.1016/j.ijthermalsci.2005. 09.006\}. URL http://linkinghub.elsevier.com/retrieve/pii/ S1290072905002164.

[183] Soderman, J., Pettersson, F.. Structural and operational optimisation of distributed energy systems. Applied Thermal Engineering 2006;26(13):1400-1408. doi:\bibinfo\{doi\}\{10.1016/j.applthermaleng. 2005.05.034\}. URL http://linkinghub.elsevier.com/retrieve/ pii/S1359431105002164.

[184] Weber, C., Maréchal, F., Favrat, D.. Design and optimization of district energy systems. In: 10th International Symposium 
on District Heating and Cooling; vol. 24. Elsevier; 2006,URL http: //linkinghub.elsevier.com/retrieve/pii/S1570794607802124.

[185] Bakken, B., Skjelbred, H., Wolfgang, O.. eTransport: Investment planning in energy supply systems with multiple energy carriers. Energy 2007;32(9):1676-1689. doi: \bibinfo\{doi\}\{10.1016/j.energy. 2007.01.003\}. URL http://linkinghub.elsevier.com/retrieve/ pii/S0360544207000175.

[186] Casisi, M., Pinamonti, P., Reini, M.. Optimal lay-out and operation of combined heat \& power (CHP) distributed generation systems. Energy 2009;34(12):2175-2183. doi: \bibinfo\{doi\}\{10.1016/j.energy.2008. 10.019\}. URL http://linkinghub.elsevier.com/retrieve/pii/ S0360544208002594.

[187] Tveit, T., Savola, T., Gebremedhin, a., Fogelholm, C.. Multiperiod MINLP model for optimising operation and structural changes to CHP plants in district heating networks with long-term thermal storage. Energy Conversion and Management 2009;50(3):639647. doi: \bibinfo\{doi\}\{10.1016/j.enconman.2008.10.010\}. URL http: //linkinghub.elsevier.com/retrieve/pii/S0196890408004159.

[188] Bojić, M., Cubrović, R.. Design method for the optimization of district heating systems using mixed integer linear programming. Proceedings of the Institution of Mechanical Engineers, Part A: Journal of Power and Energy 2010;224(5):607-619. doi: \bibinfo\{doi $\}\{10$. 1243/09576509JPE911\}. URL http://journals .pepublishing.com/ openurl . asp?genre=article\&id=doi:10 .1243/09576509JPE911.

[189] Ren, H., Gao, W.. A MILP model for integrated plan and evalua- 
tion of distributed energy systems. Applied Energy 2010;87(3):10011014. doi: \bibinfo\{doi $\}\{10.1016 / j$.apenergy.2009.09.023\}. URL http: //linkinghub.elsevier.com/retrieve/pii/S0306261909004152.

[190] Zavadskas, E., Kaklauskas, A., Raslanas, S.. Evaluation of investments into housing renovation. International Journal of Strategic Property Management 2004;8(3):177-190. doi: \bibinfo\{doi\}\{10. 1080/1648715X.2004.9637516\}. URL http://www.informaworld. com/index/928272824.pdf.

[191] Fleten, S., Maribu, K., Wangensteen, I.. Optimal investment strategies in decentralized renewable power generation under uncertainty. Energy 2007;32(5):803-815. doi:\bibinfo\{doi\}\{10.1016/j.energy.2006. 04.015\}. URL http://linkinghub.elsevier.com/retrieve/pii/ S0360544206001150.

[192] Ooka, R., Komamura, K.. Optimal design method for building energy systems using genetic algorithms. Building and Environment 2009;44(7):1538-1544. doi: \bibinfo\{doi\}\{10.1016/j.buildenv. 2008.07.006\}. URL http://linkinghub.elsevier.com/retrieve/ pii/S0360132308001820.

[193] Amano, Y., Ito, K., Yoshida, S., Matsuo, K., Hashizume, T., Favrat, D., et al. Impact analysis of carbon tax on the renewal planning of energy supply system for an office building. Energy 2010;35(2):10401046. doi: \bibinfo\{doi\}\{10.1016/j.energy.2009.06.023\}. URL http: //linkinghub.elsevier.com/retrieve/pii/S0360544209002370.

[194] Brownsword, R., Fleming, P., Powell, J., Pearsall, N.. Sustainable cities - modelling urban energy supply and demand. Applied En- 
ergy 2005;82(2):167-180. doi: bibinfo\{doi\}\{10.1016/j.apenergy.2004. 10.005\}. URL http://linkinghub.elsevier.com/retrieve/pii/ S0306261904001679.

[195] Sirikitputtisak, T., Mirzaesmaeeli, H., Douglas, P.L., Croiset, E., Elkamel, A., Gupta, M.. A multi-period optimization model for energy planning with CO2 emission considerations. Energy Procedia 2009;1(1):4339-4346. doi: \bibinfo\{doi\}\{10.1016/j.egypro.2009. 02.247\}. URL http://linkinghub.elsevier.com/retrieve/pii/ S187661020900890X.

[196] Lin, Q., Huang, G.. A dynamic inexact energy systems planning model for supporting greenhouse-gas emission management and sustainable renewable energy development under uncertainty - A case study for the City of Waterloo, Canada. Renewable and Sustainable Energy Reviews 2009;13(8):1836-1853. doi: \bibinfo\{doi\}\{10.1016/j.rser.2009. 01.021\}. URL http://linkinghub.elsevier.com/retrieve/pii/ S1364032109000367.

[197] Lin, Q., Huang, G.. An inexact two-stage stochastic energy systems planning model for managing greenhouse gas emission at a municipal level. Energy 2010;35(5):2270-2280. doi: \bibinfo\{doi\} \{10.1016/j.energy.2010.01.042\}. URL http://linkinghub.elsevier. com/retrieve/pii/S036054421000068X.

[198] Bhatt, V., Friley, P., Lee, J.. Integrated energy and environmental systems analysis methodology for achieving low carbon cities. Journal of Renewable and Sustainable Energy 2010;2(3):031012. doi: \bibinfo\{doi $\}\{10.1063 / 1.3456367\}$. URL http://link.aip.org/ link/JRSEBH/v2/i3/p031012/s1\&Agg=doi. 
[199] Difs, K., Bennstam, M., Trygg, L., Nordenstam, L.. Energy conservation measures in buildings heated by district heating - A local energy system perspective. Energy 2010;35(8):3194-3203. doi: \bibinfo\{doi\} $\{10.1016 /$ j.energy.2010.04.001\}. URL http://linkinghub.elsevier. com/retrieve/pii/S0360544210001921.

[200] Weber, C., Shah, N.. Optimisation based design of a district energy system for an eco-town in the United Kingdom. Energy 2011;36(2):1292-1308. doi: \bibinfo\{doi\}\{10.1016/j.energy.2010. 11.014\}. URL http://linkinghub.elsevier.com/retrieve/pii/ S0360544210006407.

[201] Zhu, Y., Huang, G., Li, Y., He, L., Zhang, X.. An interval full-infinite mixed-integer programming method for planning municipal energy systems - A case study of Beijing. Applied Energy 2011;88(8):2846-2862. doi: \bibinfo\{doi\}\{10.1016/j.apenergy. 2011.01.058\}. URL http://linkinghub.elsevier.com/retrieve/ pii/S0306261911000766.

[202] Rolfsman, B.. Optimal supply and demand investments in municipal energy systems. Energy Conversion and Management 2004;45(4):595611. doi: bibinfo\{doi\}\{10.1016/S0196-8904(03)00174-2\}. URL http: //linkinghub.elsevier.com/retrieve/pii/S0196890403001742.

[203] Adamo, L., Cammarata, G., Fichera, A., Marletta, L.. Improvement of a district heating network through thermoeconomic approach. Renewable Energy 1997;10(213):213-216. URL http://linkinghub. elsevier.com/retrieve/pii/0960148196000663.

[204] Bruckner, T., Groscurth, H., Kummel, R.. Competition 
and synergy between energy technologies in municipal energy systems. Energy 1997;22(10):1005-1014. doi: \bibinfo\{doi\}\{10.1016/ S0360-5442(97)00037-6\}. URL http://linkinghub.elsevier.com/ retrieve/pii/S0360544297000376.

[205] Groscurth, H., Bruckner, T., Kummel, R.. Modeling of energy-services supply systems. Energy 1995;20(9):941-958. doi: bibinfo $\{$ doi $\}\{10.1016 / 0360-5442(95) 00067-Q\}$. URL http:// linkinghub.elsevier.com/retrieve/pii/036054429500067Q.

[206] Lindenberger, D.. Optimization of solar district heating systems: seasonal storage, heat pumps, and cogeneration. Energy 2000;25(7):591608. doi: bibinfo\{doi\}\{10.1016/S0360-5442(99)00082-1\}. URL http: //linkinghub.elsevier.com/retrieve/pii/S0360544299000821.

[207] Benonysson, A., Bø hm, B., Ravn, H.. Operational optimization in a district heating system. Energy conversion and management 1995;36(5):297-314. URL http://linkinghub.elsevier.com/ retrieve/pii/019689049598895T.

[208] Hu, D., You, F., Zhao, Y., Yuan, Y., Liu, T., Cao, A., et al. Input, stocks and output flows of urban residential building system in Beijing city, China from 1949 to 2008. Resources, Conservation and Recycling 2010;54(12):1177-1188. doi: \bibinfo\{doi\}\{10.1016/j.resconrec. 2010.03.011\}. URL http://linkinghub.elsevier.com/retrieve/ pii/S0921344910000868.

[209] Páez, A.. Energy-urban transition: The Mexican case. Energy Policy 2010;38(11):7226-7234. doi: \bibinfo $\{$ doi $\}\{10.1016 / j . e n p o l .2010$. 
07.053\}. URL http://linkinghub.elsevier.com/retrieve/pii/ S0301421510005835.

[210] Chang, L., Li, Z., Gao, D., Huang, H., Ni, W.. Pathways for hydrogen infrastructure development in China: Integrated assessment for vehicle fuels and a case study of Beijing. Energy 2007;32(11):20232037. doi: \bibinfo\{doi\}\{10.1016/j.energy.2007.04.003\}. URL http: //linkinghub.elsevier.com/retrieve/pii/S0360544207000679.

[211] Lucon, O., dos Santos, E.. The HORUS model: inventory of atmospheric pollutant emissions from industrial combustion in Sao Paulo, Brazil. Environmental Impact Assessment Review 2005;25(2):197214. doi: \bibinfo\{doi $\}\{10.1016 /$ j.eiar.2004.06.010\}. URL http:// linkinghub.elsevier.com/retrieve/pii/S0195925504000794.

[212] Kuronen, M., Junnila, S., Majamaa, W., Niiranen, I.. PublicPrivate-People Partnership as a Way to Reduce Carbon Dioxide Emissions from Residential Development. International Journal of Strategic Property Management 2010;14(3):200-216. doi: \bibinfo\{doi\} $\{10.3846 /$ ijspm.2010.15\}. URL http://versita.metapress.com/ openurl . asp?genre=article\&id=doi : 10.3846/ijspm. 2010.15.

[213] Crawford-Brown, D.. A'Samaliah island, UAE: a case study in sustainability. Proceedings of the ICE - Civil Engineering 2009;162(6):60-64. doi: \bibinfo $\{$ doi $\}\{10.1680 /$ cien.2009.162.6. 60\}. URL http://www.icevirtuallibrary.com/content/article/ 10.1680/cien.2009.162.6.60.

[214] Kenworthy, J.R.. The eco-city: ten key transport and planning dimensions for sustainable city development. Environment 
and Urbanization 2006;18(1):67-85. doi:\bibinfo $\{$ doi $\}\{10.1177 /$ 0956247806063947\}. URL http://eau.sagepub.com/cgi/doi/10. $1177 / 0956247806063947$.

[215] Lo, S.. Domestic energy use and air quality; a case study of the city of Belfast. Applied Energy 2001;68(1):1-18. doi: \bibinfo\{doi\}\{10.1016/ S0306-2619(00)00044-1\}. URL http://linkinghub.elsevier.com/ retrieve/pii/S0306261900000441.

[216] van der Vleuten, E., Raven, R.. Lock-in and change: Distributed generation in Denmark in a long-term perspective. Energy Policy 2006;34(18):3739-3748. doi: \bibinfo\{doi\}\{10.1016/j.enpol.2005. 08.016\}. URL http://linkinghub.elsevier.com/retrieve/pii/ S030142150500220X.

[217] Ornetzeder, M., Hertwich, E.G., Hubacek, K., Korytarova, K., Haas, W.. The environmental effect of car-free housing: A case in Vienna. Ecological Economics 2008;65(3):516-530. doi: \bibinfo\{doi $\}\{10$. 1016/j.ecolecon.2007.07.022\}. URL http://linkinghub.elsevier. com/retrieve/pii/S0921800907004090.

[218] Larivière, I.. Modelling the electricity consumption of cities: effect of urban density. Energy Economics 1999;21(1):53-66. doi: bibinfo\{doi\}\{10.1016/S0140-9883(98)00007-3\}. URL http:// linkinghub.elsevier.com/retrieve/pii/S0140988398000073.

[219] Newman, P., Kenworthy, J., Lyons, T.. The ecology of urban driving II-driving cycles across a city: Their validation and implications. Transportation Research Part A: Policy and Practice 1992;26(3):273- 
290. doi:〈bibinfo $\{$ doi $\}\{10.1016 / 0965-8564(92) 90037-8\}$. URL http: //linkinghub.elsevier.com/retrieve/pii/0965856492900378.

[220] Ouedraogo, B.. Household energy preferences for cooking in urban Ouagadougou, Burkina Faso. Energy Policy 2006;34(18):37873795. doi: \bibinfo\{doi\}\{10.1016/j.enpol.2005.09.006\}. URL http: //linkinghub.elsevier.com/retrieve/pii/S0301421505002399.

[221] Arthur, M.d.F.S., Zahran, S., Bucini, G.. On the adoption of electricity as a domestic source by Mozambican households. Energy Policy 2010;38(11):7235-7249. doi:〈bibinfo\{doi\}\{10.1016/j.enpol.2010. 07.054\}. URL http://linkinghub.elsevier.com/retrieve/pii/ S0301421510005847.

[222] Gundimeda, H., Köhlin, G.. Fuel demand elasticities for energy and environmental policies: Indian sample survey evidence. Energy Economics 2008;30(2):517-546. doi:〈bibinfo\{doi\}\{10.1016/j.eneco.2006. 10.014\}. URL http://linkinghub.elsevier.com/retrieve/pii/ S0140988306001290.

[223] Choi, S.W., Sohngen, B., Alig, R.. An assessment of the influence of bioenergy and marketed land amenity values on land uses in the Midwestern US. Ecological Economics 2011;70(4):713720. doi:〈bibinfo\{doi\}\{10.1016/j.ecolecon.2010.11.005\}. URL http: //linkinghub.elsevier.com/retrieve/pii/S0921800910004581.

[224] Yang, Z.F., Zhao, W.. Analysis on Evolution of Urban Energy System Structure Based on Information Entropy. Energy Sources, Part A: Recovery, Utilization, and Environmental Effects 2008;30(14):1400-1412. doi:〈bibinfo $\{$ doi $\}\{10.1080 /$ 
15567030801929142\}. URL http://www.informaworld.com/ openurl?genre=article\&doi=10 $.1080 / 15567030801929142 \mathrm{kmagic}=$ crossref | |D404A21C5BB053405B1A640AFFD44AE3.

[225] Filion, Y.R.. Impact of Urban Form on Energy Use in Water Distribution Systems. Journal of Infrastructure Systems 2008;14(4):337. doi: bibinfo $\{$ doi $\}\{10.1061 /($ ASCE)1076-0342(2008)14:4(337).$\quad$ URL http://link.aip.org/link/JITSE4/v14/i4/p337/s1\&Agg=doi.

[226] Shimoda, Y., Okamura, T., Yamaguchi, Y., Yamaguchi, Y., Taniguchi, A., Morikawa, T.. City-level energy and CO2 reduction effect by introducing new residential water heaters. Energy 2010;doi: bibinfo\{doi\}\{10.1016/j.energy.2010.08.043\}. URL http:// linkinghub.elsevier.com/retrieve/pii/S0360544210004792.

[227] Shimoda, Y., Yamaguchi, Y., Okamura, T., Taniguchi, A., Yamaguchi, Y.. Prediction of greenhouse gas reduction potential in Japanese residential sector by residential energy end-use model. Applied Energy 2010;87(6):1944-1952. doi: \bibinfo\{doi\}\{10.1016/ j.apenergy.2009.10.021\}. URL http://linkinghub.elsevier.com/ retrieve/pii/S0306261909004656.

[228] Martins, L.D., Andrade, M.F.. Emission Scenario Assessment of Gasohol Reformulation Proposals and Ethanol Use in the Metropolitan Area of Sao Paulo. The Open Atmospheric Science Journal 2008;2(1):166-175. doi: \bibinfo\{doi\}\{10.2174/1874282300802010166\}. URL http://www.bentham-open.org/pages/content.php?TOASCJ/ 2008/00000002/00000001/166TOASCJ .SGM.

[229] Johnston, R.A.. Indicators for Sustainable Transportation Plan- 
ning. Transportation Research Record: Journal of the Transportation Research Board 2008;2067(-1):146-154. doi: \bibinfo\{doi\}\{10.3141/ 2067-17\}. URL http://trb.metapress.com/openurl.asp?genre= article\&id=doi:10.3141/2067-17.

[230] Brosthaus, J.. TÜV emission simulation model TESM: 'Tool for scenario-calculations and necessary input for dispersion modelling'. The Science of The Total Environment 1999;235(1-3):375377. doi: \bibinfo\{doi\}\{10.1016/S0048-9697(99)00239-9\}. URL http: //linkinghub.elsevier.com/retrieve/pii/S0048969799002399.

[231] García, C.A., Manzini, F., Islas, J.. Air emissions scenarios from ethanol as a gasoline oxygenate in Mexico City Metropolitan Area. Renewable and Sustainable Energy Reviews 2010;14(9):3032-3040. doi: $\backslash$ bibinfo\{doi\}\{10.1016/j.rser.2010.07.011\}. URL http://linkinghub. elsevier.com/retrieve/pii/S1364032110001917.

[232] Huang, Z., Zhang, X.. Well-to-wheels analysis of hydrogen based fuel-cell vehicle pathways in Shanghai. Energy 2006;31(4):471489. doi: \bibinfo $\{$ doi $\}\{10.1016 /$ j.energy.2005.02.019\}. URL http: //linkinghub.elsevier.com/retrieve/pii/S0360544205000617.

[233] Pohekar, S.. Application of multi-criteria decision making to sustainable energy planning-A review. Renewable and Sustainable Energy Reviews 2004;8(4):365-381. doi: \bibinfo\{doi\}\{10.1016/j.rser. 2003.12.007\}. URL http://linkinghub.elsevier.com/retrieve/ pii/S1364032104000073

[234] Kambo, N., Handa, B., Bose, R.. A linear goal programming model for urban energy-economy-environment interaction. Energy and Build- 
ings 1991;16(1-2):537-551. doi: \bibinfo\{doi $\{$ 10.1016/0378-7788(91) 90022-U\}. URL http://linkinghub.elsevier.com/retrieve/pii/ $037877889190022 \mathrm{U}$.

[235] Ramanathan, R.. A multi-objective evaluation of decentralized electricity generation options available to urban households. Energy Conversion and Management 1994;35(8):661-670. doi: \bibinfo\{doi\}\{10. 1016/0196-8904(94)90049-3\}. URL http://linkinghub.elsevier. com/retrieve/pii/0196890494900493.

[236] Rosenfeld, Y.. Decision support model for semi-automated selection of renovation alternatives. Automation in Construction 1999;8(4):503510. doi: bibinfo $\{$ doi $\}\{10.1016 /$ S0926-5805(98)00097-1\}. URL http: //linkinghub.elsevier.com/retrieve/pii/S0926580598000971.

[237] Alanne, K.. Selection of renovation actions using multi-criteria "knapsack" model. Automation in Construction 2004;13(3):377391. doi: \bibinfo $\{$ doi $\}\{10.1016 /$ j.autcon.2003.12.004\}. URL http: //linkinghub.elsevier.com/retrieve/pii/S0926580503001420.

[238] Zavadskas, E., Raslanas, S., Kaklauskas, A.. The selection of effective retrofit scenarios for panel houses in urban neighborhoods based on expected energy savings and increase in market value: The Vilnius case. Energy and Buildings 2008;40(4):573-587. doi: \bibinfo\{doi $\}\{10$. 1016/j.enbuild.2007.04.015\}. URL http://linkinghub.elsevier. com/retrieve/pii/S0378778807001405.

[239] Browne, D., O’Regan, B., Moles, R.. Use of multi-criteria decision analysis to explore alternative domestic energy and electricity policy scenarios in an Irish city-region. Energy 2010;35(2):518- 
528. doi: \bibinfo $\{$ doi $\}\{10.1016 /$ j.energy.2009.10.020\}. URL http: //linkinghub.elsevier.com/retrieve/pii/S0360544209004538.

[240] Barker, T., Anger, A., Dessens, O., Pollitt, H., Rogers, H., Scrieciu, S., et al. Integrated modelling of climate control and air pollution: Methodology and results from one-way coupling of an energy-environment-economy (E3MG) and atmospheric chemistry model (p-TOMCAT) in decarbonising scenarios for Mexico to 2050. Environmental Science \& Policy 2010;13(8):661-670. doi: \bibinfo\{doi\} $\{10.1016 /$ j.envsci.2010.09.008\}. URL http://linkinghub.elsevier. com/retrieve/pii/S1462901110001188.

[241] Pataki, D., Emmi, P., Forster, C., Mills, J., Pardyjak, E., Peterson, T., et al. An integrated approach to improving fossil fuel emissions scenarios with urban ecosystem studies. Ecological Complexity 2009;6(1):1-14. doi: \bibinfo\{doi $\}\{10.1016 / j$.ecocom. 2008.09.003\}. URL http://linkinghub.elsevier.com/retrieve/ pii/S1476945X08000494.

[242] Bhattacharyya, S.C., Timilsina, G.R.. Energy Demand Models for Policy Formulation: A Comparative Study of Energy Demand Models; 2009. URL http://www-wds.worldbank.org/ servlet/WDSContentServer/WDSP/IB/2009/03/17/000158349_ 20090317093816/Rendered/PDF/WPS4866.pdf.

[243] Batty, M., Kitchin, R., Thrift, N.. Urban Modelling. 2007. URL http://www.casa.ucl.ac.uk/andrew/repastmodels/ presentations/Urban-Modelling-Revised1.pdf.

[244] Miller, E., Hunt, J.D., Abraham, J., Salvini, P.. Microsim- 
ulating urban systems. Computers, Environment and Urban Systems 2004;28(1-2):9-44. doi: \bibinfo\{doi\}\{10.1016/S0198-9715(02) 00044-3\}. URL http://linkinghub.elsevier.com/retrieve/pii/ S0198971502000443.

[245] Bhat, C., Waller, T.. CEMDAP: A Second Generation ActivityBased Travel Modeling System for Metropolitan Areas. In: Presented at the 2008 TRB Innovations in Travel Modeling conference. Portland, Oregon; 2008,.

[246] Sivakumar, A., Keirstead, J., Polak, J.. Integrated Modelling of the Demand and Supply Vectors in Urban Energy Systems: Conceptual and Modelling Frameworks for the Development of a New Toolkit. In: European Transport Conference. Glasgow; 2010,

[247] Brownsword, R., Fleming, P., Powell, J., Pearsall, N.. Sustainable cities - modelling urban energy supply and demand. Applied Energy 2005;82(2):167-180. doi: \bibinfo\{doi\}\{10.1016/j.apenergy.2004. 10.005\}. URL http://linkinghub.elsevier.com/retrieve/pii/ S0306261904001679.

[248] Ghauche, A.. Integrated Transportation and Energy Activity-Based Model. Mst; MIT; 2010.

[249] Wegener, M.. Operational Urban Models State of the Art. Journal of the American Planning Association 1994;60(1):1729. doi: \bibinfo $\{$ doi $\}\{10.1080 / 01944369408975547\}$. URL http://tandfprod.literatumonline.com/doi/abs/10.1080/ 01944369408975547. 
[250] Wegener, M.. Overview of land use transport models. In: Hensher, D.A., Button, K., editors. Handbook of transport geography and spatial systems; chap. 9. Kidlington: Pergamon, Elsevier Science Ltd; 2004, p. 127-146. URL http: //books.google.co.uk/books?hl=en\&lr=\&id=WM006zpfUy8C\&oi= fnd\&pg=PA127\&dq=Integrated+land+use+?+transport+models + +mackett\&ots=QvHgN466ku\&sig=0osY-fXi3woQms4Ug7UDkjER_WQ.

[251] Hunt, J.. Integrated Land Use Transport Models. In: TRB Workshop 162 on Integrated Land Use-Transport Models. Washington, DC; 2005,.

[252] Wagner, P., Wegener, M.. Urban land use, transport and environment models: experiences with an integrated microscopic approach. disP 2007;170(3):46 - 56. URL http://www.citeulike.org/user/ pierreschmitt/article/7926857.

[253] Lowry, I.S.. A Model of Metropolis. Tech. Rep.; RAND Corporation Research; 1964.

[254] Mackett, R.L.. The Leeds Integrated Land-use Transport Model (LILT). Tech. Rep.; Transport and Road Research Laboratory; 1983.

[255] Putman, S.. EMPAL and DRAM Location and Land-use Models: An Overview. In: Land use Modelling Conference. Dallas, Texas; 1995,.

[256] Anderstig, C., Mattsson, L.G.. An integrated model of residential and employment location in a metropolitan region. Papers in Regional Science 1991;70(2):167-184. doi: \bibinfo\{doi\} \{10.1111/j.1435-5597.1991. tb01726.x\}. URL http://doi.wiley.com/10.1111/j.1435-5597. 1991.tb01726.x. 
[257] Martinez, F.J.. MUSSA: a land use model for Santiago City. Transportation Research Record 1996;1552:126-134.

[258] Hunt, J.D., Simmonds, D.C.. Theory and application of an integrated land-use and transport modelling framework. Environment and Planning B: Planning and Design 1993;20(2):221-244. doi: \bibinfo\{doi\} $\{10.1068 /$ b200221\}. URL http://www.envplan.com/abstract.cgi? $i d=b 200221$.

[259] de la Barra, T.. Integrated Land Use and Transport Modelling. Cambridge: Cambridge University Press; 1989.

[260] Simmonds, D.C.. The design of the DELTA land-use modelling package. Environment and Planning B: Planning and Design 1999;26(5):665-684. doi: \bibinfo $\{$ doi $\}\{10.1068 / b 260665\}$. URL http://www.envplan.com/abstract.cgi?id=b260665.

[261] Waddell, P.. UrbanSim: Modeling Urban Development for Land Use, Transportation, and Environmental Planning. Journal of the American Planning Association 2002;68(3):297-314. URL http:// WWw.informaworld.com/10.1080/01944360208976274.

[262] Alberti, M., Waddell, P.. An integrated urban development and ecological simulation model. Integrated Assessment 2000;1(3):215227. doi: \bibinfo\{doi $\}\{10.1080 / 03768359508439866\}$. URL http: //www.springerlink.com/index/q25603210564u474.pdf.

[263] Muller, K., Axhausen, K.. Population Synthesis for Microsimulation: State of the Art. In: Transportation Research Board annual conference. Washington, DC; 2011,. 
[264] Lautso, K., Spiekermann, K., Wegener, M., Sheppard, I., Steadman, P., Martino, A., et al. Planning and research of policies for land use and transport for increasing urban sustainability. Tech. Rep.; PROPOLIS Final Report, European Commission, Energy, Environment and Sustainable Development Thematic Programme of the Fifth RTD Framework Programme; 2004.

[265] Strauch, D., Moeckel, R., Wegener, M., Gräfe, J., Muhlhans, H., Rindsfuser, G., et al. Linking transport and land use planning: the microscopic dynamic simulation model ILUMASS. In: Atkinson, P.M., Foody, G.M., Darby, S.E., Wu, F., editors. Geodynamics. Boca Raton, Florida: CRC Press; 2005, p. 295-311.

[266] Czachorski, M., Silvis, J., Barkalow, G., Spiegel, L., Coldwell, M.. Development of an energy module for IPLACE3S. Tech. Rep. September 2008; California Energy Commission; 2008. URL http://www.energy.ca.gov/2008publications/ CEC-500-2008-024/CEC-500-2008-024.PDF.

[267] Kazuaki, M.. Sustainable urban planning based on integrated landuse and transportation models. In: Presented at Asian Development Bank. 2006,URL http://www.adb.org/urbandev/documents/ SustainableUrbanPlanning-K.Miyamoto.ppt.

[268] Bhat, C., Guo, J., Srinivasan, S., Sivakumar, A.. A Comprehensive Econometric Microsimulator for Daily Activity-Travel Patterns. Transportation Research Record 2004;1894.

[269] Arentze, T., Timmermans, H.. The ALBATROSS System. In: Arentze, T., Timmermans, H., editors. ALBATROSS: A Learning Based 
Transportation Oriented Simulation System. Eindhoven: European Institute of Retailing and Services Studies; 2000,.

[270] Pendyala, R., Kitamura, R., Reddy, D.. A rule-based activitytravel scheduling algorithm integrating neural networks of behavioral adaptation. In: EIRASS Conference on Activity-Based Approaches. Eindhoven; 1995,.

[271] Roorda, M., Miller, E., Habib, K.. Validation of TASHA: A 24-h activity scheduling microsimulation model. Transportation Research Part A: Policy and Practice 2008;42(2):360-375. doi: \bibinfo\{doi $\}\{10$. 1016/j.tra.2007.10.004\}. URL http://linkinghub.elsevier.com/ retrieve/pii/S0965856407000924.

[272] Waddell, P.. Integrated land use and transportation planning and modelling: Addressing challenges in research and practice. Transport Reviews 2011;31(2):209-229. doi: bibinfo\{doi\}\{10.1080/ 01441647.2010.525671\}. URL http://www.tandfonline.com/doi/ abs/10.1080/01441647.2010.525671.

[273] Hägerstrand, T.. What about people in regional science? Papers of the Regional Science Association 1970;14(7-21).

[274] Jones, P., Dix, M., Clarke, M., Heggie, I.. Understanding Travel Behaviour. Aldershot: Gower; 1983.

[275] Lenntorp, B.. A time-geographic study of movement possibilities of individuals. Tech. Rep.; The Royal University Of Lund; Lund; 1976.

[276] McFadden, D.. Modelling the choice of residential location. In: Karlquist, A., editor. Spatial Interaction Theory and Planning Models; chap. 25. Amsterdam; 1978, p. 75-96. 
[277] Train, K.. Discrete Choice Methods with Simulation. Cambridge: Cambridge University Press; 2003.

[278] Alarcon-Rodriguez, A., Ault, G., Galloway, S.. Multi-objective planning of distributed energy resources: A review of the state-of-the-art. Renewable and Sustainable Energy Reviews 2010;14(5):1353-1366. doi: $\backslash$ bibinfo\{doi\}\{10.1016/j.rser.2010.01.006\}. URL http://linkinghub. elsevier.com/retrieve/pii/S1364032110000146.

[279] Chantrelle, F.P., Lahmidi, H., Keilholz, W., Mankibi, M.E., Michel, P.. Development of a multicriteria tool for optimizing the renovation of buildings. Applied Energy 2011;88(4):1386-1394. doi: \bibinfo\{doi $\}\{10$. 1016/j.apenergy.2010.10.002\}. URL http://linkinghub.elsevier. com/retrieve/pii/S0306261910003971.

[280] Ascher, W.. Forecasting: An Appraisal for Policy-Makers and Planners. John Hopkins University Press; 1978.

[281] Koomey, J., Craig, P., Gadgil, A., Lorenzetti, D.. Improving long-range energy modeling: A plea for historical retrospectives. The Energy Journal 2003;24(4):75-92. URL http://eande. lbl .gov/iep/ pdf/LBNL-52448.pdf.

[282] Ekechukwu, O., Madu, A., Nwanya, S., Agunwamba, J.. Optimization of energy and manpower requirements in Nigerian bakeries. Energy Conversion and Management 2011;52(1):564-568. doi: bibinfo\{doi\}\{10.1016/j.enconman.2010.07.031\}. URL http:// linkinghub.elsevier.com/retrieve/pii/S0196890410003389.

[283] Verderame, P.M., Elia, J.a., Li, J., Floudas, C.a.. Planning and Scheduling under Uncertainty: A Review Across Multiple Sectors. In- 
dustrial \& Engineering Chemistry Research 2010;49(9):3993-4017. doi: $\backslash$ bibinfo $\{$ doi $\}\{10.1021 /$ ie902009k . URL http://pubs .acs.org/doi/ abs/10.1021/ie902009k.

[284] Lautso, K., Spiekermann, K., Wegener, M., Sheppard, I., Steadman, P., Martino, A., et al. Planning and research of policies for land use and transport for increasing urban sustainability. Tech. Rep.; PROPOLIS Final Report, European Commission, Energy, Environment and Sustainable Development Thematic Programme of the Fifth RTD Framework Programme; 2004.

[285] Johnson, M., Suskewicz, J.. How to Jump Start the Clean Tech Economy. Harvard Business Review 2009;:52-60.

[286] Saltelli, A., Ratto, M., Andres, T., Campolongo, F., Cariboni, J., Gatelli, D., et al. Global Sensitivity Analysis: The Primer. WileyBlackwell; 2008. ISBN 0470059974. URL http://www. amazon.co.uk/ Global-Sensitivity-Analysis-Andrea-Saltelli/dp/0470059974.

[287] Hall, J.W., Boyce, S.a., Wang, Y., Dawson, R.J., Tarantola, S., Saltelli, A.. Sensitivity Analysis for Hydraulic Models. Journal of Hydraulic Engineering 2009;135(11):959. doi: bibinfo\{doi\}\{10.1061/ (ASCE)HY.1943-7900.0000098\}. URL http://link.aip.org/link/ JHEND8/v135/i11/p959/s1\&Agg=doi.

[288] de Rocquigny, E., Devictor, N., Tarantola, S.. Uncertainty in Industrial Practice: A guide to quantitative uncertainty management. Wiley; 2008.

[289] Lin, Q., Huang, G.. A dynamic inexact energy systems planning model for supporting greenhouse-gas emission management and sustainable 
renewable energy development under uncertainty-A case study for the City of Waterloo, Canada. Renewable and Sustainable Energy Reviews 2009;13(8):1836-1853. doi: \bibinfo\{doi\}\{10.1016/j.rser.2009. 01.021\}. URL http://linkinghub.elsevier.com/retrieve/pii/ S1364032109000367.

[290] Huang, Y., Fan, Y., Johnson, N.. Multistage System Planning for Hydrogen Production and Distribution. Networks and Spatial Economics 2009;10(4):455-472. doi: \bibinfo\{doi $\}\{10$. 1007/s11067-009-9119-6\}. URL http://www.ingentaconnect.com/ content/klu/nets/2010/00000010/00000004/00009119.

[291] Lozano, M.A., Ramos, J.C., Carvalho, M., Serra, L.M.. Structure optimization of energy supply systems in tertiary sector buildings. Energy and Buildings 2009;41(10):1063-1075. doi: \bibinfo\{doi $\}\{10$. 1016/j.enbuild.2009.05.008\}. URL http://linkinghub.elsevier. com/retrieve/pii/S037877880900111X.

[292] Armbrust, M., Joseph, A.D., Katz, R.H., Patterson, D.A.. Above the Clouds : A Berkeley View of Cloud Computing. Tech. Rep.; Electrical Engineering and Computer Sciences, University of California at Berkeley; Berkeley, CA; 2009. URL http://www.eecs . berkeley.edu/ Pubs/TechRpts/2009/EECS-2009-28.html.

[293] Buyya, R., Yeo, C.S., Venugopal, S., Broberg, J., Brandic, I.. Cloud computing and emerging IT platforms: Vision, hype, and reality for delivering computing as the 5th utility. Future Generation Computer Systems 2009;25(6):599-616. doi: \bibinfo\{doi\}\{10.1016/j.future. 2008.12.001\}. URL http://linkinghub.elsevier.com/retrieve/ pii/S0167739X08001957. 
[294] Hayes, B.. Cloud computing. Communications of the ACM 2008;51(7):9. doi:〈bibinfo\{doi\}\{10.1145/1364782.1364786\}. URL http://portal.acm.org/citation. cfm?doid=1364782.1364786.

[295] Keahey, K., Freeman, T.. Science Clouds : Early Experiences in Cloud Computing for Scientific Applications. Tech. Rep.; Nimbus; 2008. URL http://www.nimbusproject.org/files/ Science-Clouds-CCA08.pdf.

[296] IPCC, . Contribution of Working Group 3 to the Fourth Assessment Report of the Intergovernmental Panel on Climate Change. Cambridge University Press; 2007. URL http://www.ipcc.ch/publications_ and_data/ar4/wg3/en/contents.html.

[297] Gruber, T.R.. Towards Principles for the Design of Ontologies Used for Knowledge Sharing. In: International Workshop on Formal Ontology. Padova; 1993,

[298] Borgman, C.L.. Scholarship in the Digital Age; Information, Infrastructure, and the Internet. MIT Press; 2007. ISBN 0-262-02619-8.

[299] Hovy, E.. Using an ontology to simplify data access. Communications of the ACM 2003;46:47-49.

[300] Keirstead, J., van Dam, K.H.. A comparison of two ontologies for agent-based modelling of energy systems. In: First International Workshop on Agent Technologies for Energy Systems. 2010, p. 21-28.

[301] Keirstead, J., van Dam, K.H.. A Survey on the Application of Conceptualisations in Energy Systems Modelling. In: Formal Ontologies Meet Industry. 2011,. 
[302] The Economist, . The data deluge. The Economist 2010;URL http: //wWW.economist.com/node/15579717.

[303] IIASA, . Major IIASA Models and Data Resources. 2011. URL http: //www.iiasa.ac.at/Research/Models/index.html?sb=18.

[304] BP, . Statistical Review of World Energy 2010. Tech. Rep.; BP p.l.c; 2011. URL http://www.bp.com/productlanding.do?categoryId= $6929 \&$ content Id $=7044622$.

[305] Eurostat, . European Commission Energy Database. 2011. URL http://epp.eurostat.ec.europa.eu/portal/page/portal/ energy/data/database.

[306] U.K. DECC, . Sub-national energy consumption statistics. 2011. URLhttp://www.decc.gov.uk/en/content/cms/statistics/ regional/regional.aspx. 